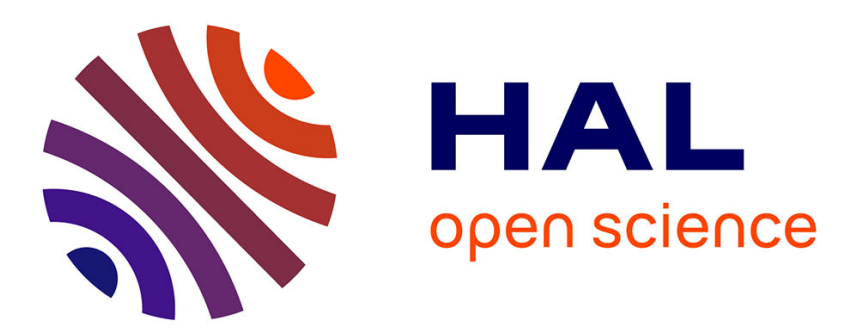

\title{
Inversion of geological knowledge for fold geometry
}

Lachlan Grose, Laurent Ailleres, Gautier Laurent, Robin Armit, Mark Jessell

\section{To cite this version:}

Lachlan Grose, Laurent Ailleres, Gautier Laurent, Robin Armit, Mark Jessell. Inversion of geological knowledge for fold geometry. Journal of Structural Geology, 2018, 119, pp.1-14. 10.1016/j.jsg.2018.11.010 . hal-01939517

\section{HAL Id: hal-01939517 \\ https://hal.univ-lorraine.fr/hal-01939517}

Submitted on 29 Nov 2018

HAL is a multi-disciplinary open access archive for the deposit and dissemination of scientific research documents, whether they are published or not. The documents may come from teaching and research institutions in France or abroad, or from public or private research centers.
L'archive ouverte pluridisciplinaire HAL, est destinée au dépôt et à la diffusion de documents scientifiques de niveau recherche, publiés ou non, émanant des établissements d'enseignement et de recherche français ou étrangers, des laboratoires publics ou privés. 


\title{
Inversion of geological knowledge for fold geometry
}

\author{
L. Grose ${ }^{1, *}$, L. Aillères ${ }^{1}$, G. Laurent ${ }^{1,2,3}$, R. Armit ${ }^{1}$, and M. Jessell ${ }^{4}$ \\ ${ }^{1}$ School of Earth, Atmosphere and Environment, Monash University PO Box 28E, Victoria, Australia \\ ${ }^{2}$ Université de Lorraine, CNRS, Laboratoire GeoRessources, 54000, Nancy, France \\ ${ }^{3}$ Univ. Orléans, CNRS, BRGM, ISTO, UMR 7327, F-45071, Orléans, France \\ ${ }^{4}$ The University of Western Australia, Centre for Exploration Targeting, School of Earth and Environment, Perth, Western Australia, Australia \\ * Corresponding author: Lachlan Grose, School of Earth, Atmosphere and Environment, PO Box 28E Monash University, Victoria, Australia. E-mail address: \\ lachlan.grose@monash.edu
}

\begin{abstract}
The process of building three-dimensional (3D) geological models can be framed as an inverse problem where a model describing the 3D distribution of rock units is non-uniquely derived from geological observations. The inverse problem theory provides a powerful framework for inferring these parameters from all geological observations, in a similar way to how a geologist can iteratively update their structural interpretation while mapping. Existing geological knowledge is usually indirectly incorporated into 3D models using the geologist's non-unique interpretation as form lines, cross sections and level maps. These approaches treat constraints derived from geological knowledge in the same way as direct observations, diluting and confusing both information provided by geological knowledge and hard data resulting in significant subjectivity. We present a geological inversion using Bayesian inference where geological knowledge can be incorporated directly into the interpolation scheme with likelihood functions and informative prior distributions. We demonstrate these approaches on a series of synthetic fold shapes as a proof of concept and a case study from the Proterozoic Davenport Province in the Northern Territory, Australia. The combined inversion of geological data and knowledge significantly reduces the uncertainty in possible fold geometries where data is sparse or highly ambiguous. This could be used by geologists while mapping to propagate information about uncertainties throughout the mapping/model building process and would allow for different structural interpretations to be rapidly tested for targeted data collection.
\end{abstract}

\section{Keywords}

Bayesian Inference

Folding

Structural Geology

Geological Uncertainty

Geological Inversion

Inverse Problem

3D Modeling

\section{IntRODUCTION}

Building three-dimensional (3D) geological models is a complicated task requiring an assimilation of available datasets, prior geological interpretation, and geological knowledge. Recent developments in 3D modeling algorithms and techniques [Calcagno et al., 2008; Massiot and Caumon, 2010; Caumon et al., 2013; Hillier et al., 2013, 2014; Laurent et al., 2016; Grose et al., 2017, 2018; Cowan et al., 2003] have significantly improved how direct observations can be used to constrain surface geometries. The process of creating 3D geological models to represent subsurface geometries can be framed as an inverse problem where the aim is to infer parameter values for the interpolation algorithm given geological observations [Grose et al., 2018]. Geological models, and as a result, geological inversions are usually under constrained. However, there are often geological rules and additional geological knowledge that are not directly incorporated into the interpolation schemes that would further constrain subsurface geometries [Jessell et al., 2010a, 2014].

A priori geological knowledge is usually indirectly incorporated into 3D models using subjective form lines, cross sections and level maps [Jessell et al., 2010a, 2014]. Usually these interpretive constraints are defined by the geologist summarising available observations and geological knowledge. The geologist's interpretation is subjective and will typically produce a single non-unique solution to a complex problem [Jones et al., 2004]. For example, the geologist may want to refine the fold style obtained by interpolating available observations, e.g. , if folds in the field have been observed to be tighter than the modeled geometries. A common way to produce expected geometries is to introduce interpretive cross-sections that locally describes the expected shape. This approach is problematic because the interpolation algorithms used for implicit modeling treat these interpretive constraints in the same way as direct observations, i.e. , they would locally define the orientation and position of the interpolated surfaces whereas the intention was only to control the fold style. When used in this way, geological knowledge results in over-constraining the range of possible results. In this paper, we propose to incorporate geological knowledge into an inverse problem framework allowing for the mathematical descriptions of geological knowledge to be used directly without requiring subjective interpretive constraints.

A new framework for modeling folded surfaces has significantly improved the incorporation of structural geology concepts [Laurent et al., 2016; Grose et al., 2017, 2018]. Using these developments, structural modeling can be framed as an inverse problem and structural data can be inverted for fold geometries [Grose et al., 2018]. This approach uses Bayesian inference to sample from the possible combination of parameters (joint posterior distribution) describing the fold axis geometry and the fold shape for local structural observations (e.g. foliations, bedding, fold axis and intersection lineations). These developments allow for refolded folds with complex non-cylindrical geometries to be modeled.

The description of an inverse problem using Bayesian inference can be easily generalised to incorporate a diverse range of observation types [Malinverno and Parker, 2006]. Wood and Curtis [2004] suggest a framework for incorporating Geological Prior Information explicitly for modeling sedimentary structures. They 
show that the addition of additional geometrical information can significantly improve the modeled sedimentary structures away from data. Wellmann et al. [2017] and de la Varga and Wellmann [2016] have used Bayesian inference to include additional information into implicit modeling schemes, for example fault displacement, layer thickness and fault movement direction. In this contribution, we incorporate geological knowledge into the inversion framework from Grose et al. [2018] using a combination of informative prior distributions and additional geological likelihood functions. This approach allows for a combined inversion of local structural observations and global geological knowledge. The probabilistic framework can also be used to determine where the model is relatively well constrained and where it is not. The combined inversion of local observations and global knowledge allows for feedback in terms of the quality of the observations, for example inconsistent observations and knowledge can be determined by analysing the joint posterior distribution. We present proof-of-concept synthetic examples to demonstrate the application of these new likelihood functions to known examples and a 3D case study from the Davenport Province in the Northern Territory, Australia. Our results show that the addition of geological knowledge significantly reduces the variability in interpolated model geometries where the direct observations are sparse or highly ambiguous. The combined inversion of geological data and knowledge provides a promising framework for real-time geological mapping where geological uncertainties can be propagated allowing for different structural interpretations to be tested, identifying targets for additional data collection.

\section{Geological KnOWLedge and interpretation}

Geologists use visual features in an outcrop to define geological observations [Rudwick, 1976; Frodeman, 1995]. These characteristics and patterns in the rocks by themselves do not provide all of the possible geological information. It is only by correlating between outcrops and applying geological rules that the observations can be related to geological features such as fault planes, tectonic cleavages or stratigraphic horizons. Frodeman [1995] argues that the process of geological reasoning defines geosciences as an interpretive and historical science, highlighting the role of interpretation, synthesis, and broader knowledge when constructing and testing hypotheses. According to Frodeman [1995], this process is iterative where the geologists interpretation is continuously updated by additional data and knowledge. Most geological observations are made in the context of the outcrop or the regional structural architecture. The local observations are then used to inform and test the understanding of the outcrop, deformational history and/or regional structures. An example of is when geologists produce a geological map by building their interpretation while mapping and using this knowledge to guide further interpretations. The creation of a geological map can be subjective and is a significant source of uncertainty as it is difficult to separate observations from interpretation [Jones et al., 2004] Although, some aspects of a geological map are less subjective, such as measuring the orientation of bedding and fault surfaces, other observations such as fault displacement and overprinting relationships can be more subjective. It also means that when creating a map, geologists generally only record their favoured interpretation and not the range of possible interpretations [Bond et al., 2007a; Riggs et al., 2009]. The geologist's interpretation is usually guided by geological knowledge to interpolate between direct observations. An alternative approach suggested by Jones et al. [2004] would be to have 'interpretation tools', effectively a geological interpolation algorithm similar to those used for 3D modeling, that can include all of the different geological observations and knowledge. These 'interpretation tools' could then be used to produce multiple possible maps/models, where the geologist's expertise can then be used to assess the validity of possible models instead of trying to construct a single model [Jessell et al., 2010b; Wijns et al., 2003].

Geological knowledge includes observations that describe the geometry of geological features but do not locally constrain the geometry of these features. They may not necessarily have an explicit location, for example inferring fold style in a fold series applies to the whole series and not only a single location in the series. Geological knowledge is updated by combining observations and geological rules for example, using observations of one structure to infer the geometry of another or by visualising the geometries that could be physically possible. Folds are often described using qualitative descriptors that also have an associated quantitative measure. For example: fold hinge geometry, fold tightness, wavelength, amplitude, symmetry, and fold vergence. These descriptive terms are difficult to turn into systematic criterion for modeling because they describe feature of the resulting model and not a direct control on the local model geometry.

In summary, the interpretation process is highly subjective and will result in a single non-unique solution to a complex problem [Jones et al., 2004; McCaffrey et al., 2005; Bond et al., 2007b]. Jones et al. [2004] suggested, that an interpolation algorithm capable of incorporating indirect geological observations would provide a way of propagating not only the uncertainty associated with each observation but also the uncertainties associated with the interpretation.

\section{Structural modeling of Folds as an inverse PROBLEM}

\subsection{Parametrisation of fold geometries}

Recent developments in implicit modeling techniques and statistical methods for characterising fold geometries have significantly improved the use of geological observations for modeling folded surfaces [Laurent et al., 2016; Grose et al., 2017, 2018]. These methods have incorporated the fundamental concepts from structural geology into implicit modeling schemes. A curvilinear coordinate system is defined to characterise the structural elements of the fold with three coordinates represented by 3D scalar fields $x, y$ and $z$. Three direction vectors $\left(e_{x}, e_{y}\right.$ and $\left.e_{z}\right)$, shown in for a schematic fold in Fig. 1A, are defined by the normalised gradient of the scalar fields representing the fold frame coordinates [Laurent et al., 2016]. The $z$ coordinate is interpolated so that $e_{z}$ is orthogonal to the axial foliation and the isosurfaces of $z$ are parallel with the axial surface of the fold. The $y$ coordinate is interpolated so that $y$ measures the distance along the axial surface of the fold and $e_{y}$ represents the trend of the fold axis. For similar folds, the geometry of the fold is the same for conformable layers and $x$ does not need to be interpolated. The orientation of the fold axis is defined locally by rotating the direction of the $y$ coordinate $\left(e_{y}\right)$ by the fold axis rotation angle $\left(\alpha_{P}\right)$ around $e_{z}$. This characterisation of the fold-axis locally throughout the model domain allows for non-cylindrical folds to be modeled when the fold-axis rotation angle varies with respect to the $y$ coordinate value. The orientation of the folded surface can then be found by rotating the fold frame around the fold-axis by the fold-limb rotation angle $\left(\alpha_{L}\right)$.

In general, these two angles may vary with respect to the three coordinates $(x, y, z)$. To represent fold geometries, we consider 

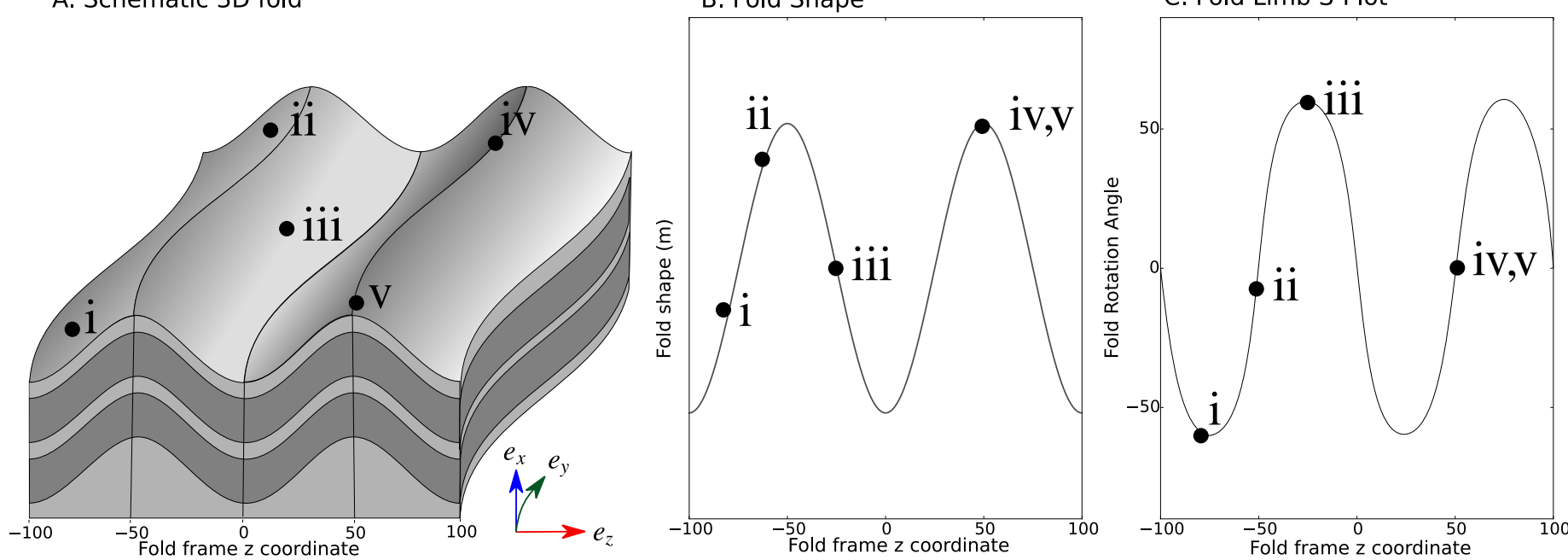

Figure 1 A: 3D diagram of a refolded fold showing folded surfaces with a deformed axial surface. $i$ and ii are locations on the same antiformal fold limb . iii corresponds to the point of inflection in one fold limb. iv and $v$ are points on the same fold hinge. B: Synthetic fold profiles representing the shape of the fold in the fold frame. The key locations in (A) are indicated in the fold profile. C: S-Plot showing fold rotation angle profile for the fold in (A) with the key locations indicated on the S-Plot. i and ii are closer in the fold frame coordinate than in Euclidean distance. Figure adapted from Grose et al. [2017]

that $\alpha_{p}$ and $\alpha_{l}$ only vary with respect to one coordinate, respectively $y$ and $z$. This simplification assumes that (1) the folds are not dying out and propagate with a same style when moving along the fold axis; and (2) the folding style is similar. While not addressed in this paper, non-similar folds can be represented with this framework assuming that $\alpha_{l}$ also varies with respect to $x$ However, the variation of this additional parameter would render the probabilistic treatment of such a dataset to be more complex, and is thus beyond the scope of this paper.

Using this scheme, fold geometries can be represented by two $1 \mathrm{D}$ curves that respectively capture the geometry of the fold axis in the axial surface, and the fold shape looking along the fold axis. Grose et al. [2017] calculate the fold rotation angles directly from structural observations and use the fold frame coordinates to extract the different elements of the fold geometry. By using the fold frame coordinates the geometry of conformable layers are extracted relative to the $z$ coordinate (Fig. 1B). The S-Plot (Fig. 1C), is a cross plot of either fold rotation angle and the associated fold frame coordinate, e.g. $\alpha_{P}$ is plotted against $y$ and $\alpha_{L}$ against $z$. The S-Plot is scale independent because it plots the fold rotation angles and not the trace of the fold shape. A sample semi-variogram (S-Variogram) also calculated on either fold rotation angle using the associated fold frame coordinate can be used to automatically identify the wavelength of folding [Grose et al., 2017]. The geometry of the fold can then be represented using two 1D Fourier series where one represents $\alpha_{P}$ for the $y$ coordinate values and another represents $\alpha_{L}$ for $z$ values. Grose et al. [2018] use these 1D functions as the forward model for a geological inversion where the fold rotation angles calculated from observations are used to falsify possible fold geometries. The unknown parameters relate to the Fourier series coefficients, fold wavelengths and a misfit parameter for each rotation angle.

\subsection{Inverse modeling of fold geometries}

The two different approaches to solving inverse problems are the Frequentist approach, using observations to directly infer the model parameters, and the Bayesian approach, using observations to modify the existing understanding of the model parameters [Tarantola, 2006]. As described in Grose et al. [2018], Bayesian inference can be used to find the joint probability distribution of possible parameters representing the fold geometry. Bayes' theorem states that the joint posterior distribution of the parameters $P(\theta \mid D)$ can be updated using the likelihood $P(D \mid \theta)$ of the data given the parameters, the prior probability of the parameters $P(\theta)$ and the probability of the data $P(D)$ :

$$
P(\theta \mid D)=\frac{P(D \mid \theta) \cdot P(\theta)}{P(D)}
$$

$P(D)$ is constant for all parameter values and means the joint posterior is proportional to the likelihood multiplied by the prior distributions. The joint posterior distribution can be sampled from using numerical techniques; in this contribution we use a Markov Chain Monte Carlo (MCMC) sampler using the MetropolisHastings algorithm implemented in PyMC2 [Patil et al., 2010].

The prior distribution of the parameters $P(\theta)$ represent prior knowledge of parameter values. Grose et al. [2018] use weakly informative priors that allow for the range in physically possible fold geometries to be modeled. The calculated fold limb rotation angle for structural data depends on the current orientation of the fold axis [Grose et al., 2017]. This relationship means that the likelihood function $P(D \mid \theta)$ has two parts, one to represent the probability of the observed fold axis rotation angle values given the parameter values and another part represents the probability of the observed fold limb rotation angle values given the parameter values for both Fourier series. Within this framework, the uncertainty in the observations can be incorporated into the description of the fold geometry representing the misfit between the model and the observations using an uninformative prior distribution, Jeffrey's prior [Sivia, 1996]. This approach means that no assumptions about the inherent uncertainty of the data is required, and a range of possible interpretations can be created from available structural data.

Grose et al. [2018] primarily consider direct structural observations and do not provide a framework for incorporating geological knowledge into the inversion. In the following section, we extend the method using additional likelihood functions and informative prior distributions that allow geological knowledge to be incorporated into the geological inversion. 

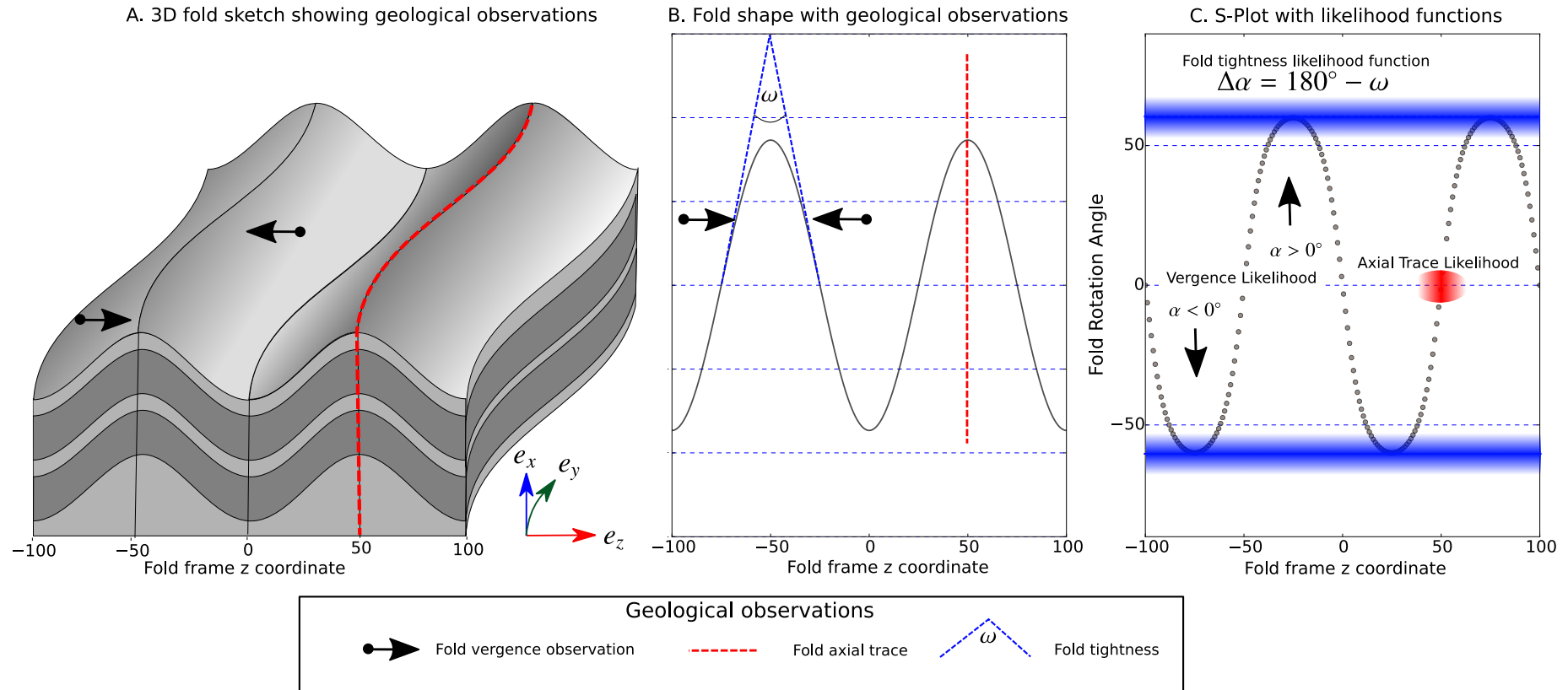

Figure $23 \mathrm{D}$ fold sketch showing knowledge likelihood. A: 3D fold sketch with two vergence observations indicating the direction to the nearest antiform and an axial trace likelihood. B: Fold shape for fold in (A) showing fold tightness, vergence observations and axial trace location. C: S-Plot showing the structural vergence enforcing the sign of the rotation angle, tightness constraints enforcing the range in rotation angle and axial trace location. The colour shading for the tightness and axial trace indicates the fuzzy nature of these constraints with darker colour indicating higher probability.

\section{Adding geological knowledge to the geologi- \\ CAL INVERSION}

The inversion of geological observations can be easily generalised using Bayesian inference to incorporate a diverse range of observations for solving the inverse problem [Malinverno and Parker, 2006]. For example, fault offset and stratigraphic unit thickness can be incorporated into geological modeling using standard implicit schemes [de la Varga and Wellmann, 2016; Wellmann et al., 2017]. This approach uses geological data as the parameters for the inverse problem and uses geological knowledge to falsify the resulting models. We propose using geological likelihood functions describing geological knowledge of folded surfaces into the fold modeling framework [Laurent et al., 2016; Grose et al., 2017, 2018].

\subsection{Fold tightness}

Fold tightness can be quantified by measuring the interlimb angle for folds (e.g. $\omega$ in Fig. 2B). More qualitatively, instead of measuring the fold interlimb angle, the fold tightness is described using the terms recommended by Fleuty [1964]. These terms each cover a small range of interlimb angles and are common nomenclature used by structural geologists when describing the shape of the fold looking down plunge. A similar measure termed hinge angle [Williams and Chapman, 1979; Bastida et al., 2005] can be used perpendicular to the fold axial surface to describe the degree of variation of the fold axis. The expected range of fold rotation angle can be calculated for the interlimb/hinge angle $(\omega)$ as $\Delta \alpha_{L, P}=180-\omega$.

Table 1 contains the different descriptive terms recommended by Fleuty [1964] and the associated range in fold tightness. These descriptive terms can be incorporated into the fold modeling framework using normal likelihood functions. The likelihood function parameters are listed in Table 1 and a Normal distribution is used where the mean $(\mu)$ is the average fold rotation angle for the fold tightness class and the standard deviation $(\sigma)$ is half of the range of the class. The likelihood function can either be
Table 1 Fold tightness descriptive terms and interlimb angle

$\begin{array}{lrr}\text { Descriptive terms } & \text { Interlimb angle } & \text { Likelihood } N(\mu, \sigma) \\ \text { gentle } & 180^{\circ}-120^{\circ} & 30^{\circ}, 30^{\circ} \\ \text { open } & 120^{\circ}-70^{\circ} & 85^{\circ}, 25^{\circ} \\ \text { close } & 70^{\circ}-30^{\circ} & 130^{\circ}, 20^{\circ} \\ \text { tight } & 30^{\circ}-0^{\circ} & 165^{\circ}, 15^{\circ} \\ \text { isoclinal } & 0^{\circ} & 180^{\circ}, 10^{\circ}\end{array}$

implemented for defined domains within the model or as a global value. In the first case, the median value of the fold rotation angle is calculated for the fold frame coordinates defining the domain. In the second example, the median value is calculated for a complete wavelength of the largest fold that will be representative for the whole model area. The calculated median value is then used in the normal likelihood function given the associated parameters in Table 1.

\subsection{Fold vergence}

Structural vergence can be obtained by finding the acute angle between two consecutive foliations. Vergence is the direction to rotate the younger foliation towards the older foliation when looking along the fold axis and indicates the direction towards the nearest antiform [Bell, 1981]. Vergence provides the structural geologist with information related to the location of fold closures that may not be visible due to outcrop limitations. Vergence can also be calculated from the asymmetry of parasitic folds where the long limb of the fold indicates the vergence direction. A similar concept can be applied to the fold axis to determine the fold plunge, which is the fold hinge-line vergence and is defined by asymmetric variations of the intersection lineation in the foliation plane [Alsop and Holdsworth, 1999]. Although the fold hinge-line vergence is not commonly observed or recorded, the geologist often has some additional knowledge about the plunge of the fold axis that could be used to infer the hinge-line vergence. 
Structural vergence and fold hinge-line vergence can be used to determine the relative sign of the fold rotation angles. Fig. 2A and $\mathrm{B}$ shows two vergence observations on a schematic 3D fold (A) and the fold shape in the fold frame coordinates (B). When plotted on the S-Plot (Fig. 2C) the vergence constraints indicate that the sign of the rotation angle should be negative at $z=-75$ and positive at $z=-25$. This criterion can be included into the inversion scheme using a likelihood function that assesses the sign of the rotation angle. We use a discrete probability density function where the probability of a consistent vergence constraint $(v=[-1,1])$ is given by:

$$
P\left(\operatorname{Sign}\left(\alpha_{L, P}\right)=v\right)=p
$$

where $p$ is the probability of the current combination of parameters being consistent with the vergence observations. We suggest that $p<1$, because if $p=1$ the probability of a conflicting constraint is 0 and therefore it is not possible for these constraints to not be honoured by the sampler.

\subsection{Fold symmetry/asymmetry}

When mapping, geologists will often be able to observe whether folds are symmetrical or asymmetrical. Fig. 3A shows a symmetrical fold shapes and Fig. 3B an asymmetrical fold shapes. The fold rotation angle of both folds are plotted in Fig. 3C. The symmetrical fold (blue curve) has a median value of $0^{\circ}$ represented by the horizontal blue line. The fold rotation angle for the asymmetrical fold (green curve) has been vertically shifted on the S-Plot and has a median fold rotation value of $40^{\circ}$ shown by the horizontal green line. Fold asymmetry and tightness both describe the fold shape and are not independent [Hudleston, 1973] The median value of the fold rotation angle depends on the tightness of the fold and the degree of asymmetry. A gentle fold that is highly asymmetrical would have a similar median value to a tight fold that is only slightly asymmetrical. The tightness and asymmetry can be separated by finding the ratio between the absolute value of the median and range of the fold rotation angle for the current model parameters. This analysis is shown in Fig. 3 where the asymmetry is shown as the absolute value of the median fold rotation angle value divided by the range of the fold rotation angle values for the curve (e.g. blue and green vertical lines in Fig. 3C).

This measure of asymmetry can then be incorporated using a normal distribution as the likelihood function assessing this ratio. When mapping, the degree of asymmetry is usually not recorded and generally folds are described as either symmetrical or asymmetrical. For this reason, we propose having a likelihood function for symmetrical folds using a normal distribution with a mean of 0 and a standard deviation of 0.1 . For asymmetrical folds, a normal distribution with a mean of 0.5 and standard deviation of 0.2 covers the range of expected fold shapes. However, these parameters can be changed or other likelihoods functions used if the geologist has more specific knowledge about the fold asymmetry. In theory, the asymmetry ratio could be calculated from outcrop observations of smaller scale asymmetrical folds However, the scale independence of fold asymmetry would need to be validated for natural folds.

\subsection{Fold wavelength}

In some cases, the data may not capture the full wavelength of the main fold geometry. For example, outcrops may only constrain the geometry of a single limb of the fold or only sam- ple a single hinge without crossing the point of inflections. In these cases, the geologist could incorporate additional information into the geological inversion, where the wavelength could be constrained by wavelength values from surrounding areas or the wavelength could be constrained from other data such as interpretation of magnetic or gravity potential field datasets. The prior distribution can either be defined by a standard probability density function (PDF) where the distribution parameters are specified by the geomodeler (e.g. for a Gaussian distribution: mean and standard deviation), or by estimating the PDF from samples (e.g. wavelength of folds from outside of the model area associated with the same deformation event) using Kernel Density Estimation (KDE).

\subsection{Interpretations: form lines and axial traces}

Form lines represent the trace of a foliation on the map surface and can either represent a direct observation of a geological feature or a combination of observation, interpretation and geological experience. Generally, there is no explicit 3D information recorded with the form lines, but it is possible to calculate the fold limb rotation angle for form lines using the geometrical relationship between the fold axis and the folded foliation. The orientation of the folded geological surface is orthogonal to both the tangent of the form line and the fold axis, and can be calculated by finding the vector product between the two normalised vectors representing the fold axis and the tangent to form line. The fold rotation angle can then be calculated for orientation measurements as detailed in Grose et al. [2017]. This knowledge can be incorporated into the geological inversion in the same way as orientation observations using a Gaussian likelihood function with an uninformative hyperparameter (Jeffrey's prior) representing the misfit between the observation and the model [Grose et al., 2018].

Fold axial traces represent the location of fold hinges and could be incorporated as additional data points constraining the fold rotation angle to be $0^{\circ}$ at that location. However, this approach does not capture the uncertainty associated with what these observations represent. A fold hinge has a fold limb rotation of $0^{\circ}$ and higher regions of uncertainty are associated with location of the fold hinge. This observation can be incorporated in the geological inversion using a separate likelihood function assessing the location of the closest fold hinge associated with the fold parameters. The likelihood is calculated using a Gaussian distribution where the mean is the axial trace fold frame coordinate value and the standard deviation is represented by Jeffrey's prior. If two fold hinges are within half of the wavelength of the axial trace constraint, the outcome is geologically unlikely and returns a minimum probability.

\subsection{Data polarity and younging}

Structural observations generally represent the unsigned orientation of the structural feature. For example, bedding observations represent the surface trend of lithological contacts, however the surface normal (younging direction) can also be recorded. By contrast, tectonic foliations lack a younging direction, and the normal to the surface cannot be related back to any observable structural information. The polarity of the observations can be adjusted by the geologist to give the most reasonable fold geometry, which in most cases is adequate, however it does introduce some additional subjectivity into the model building process. It is possible to incorporate this uncertainty into the geological inversion by modifying the Fourier series model. 

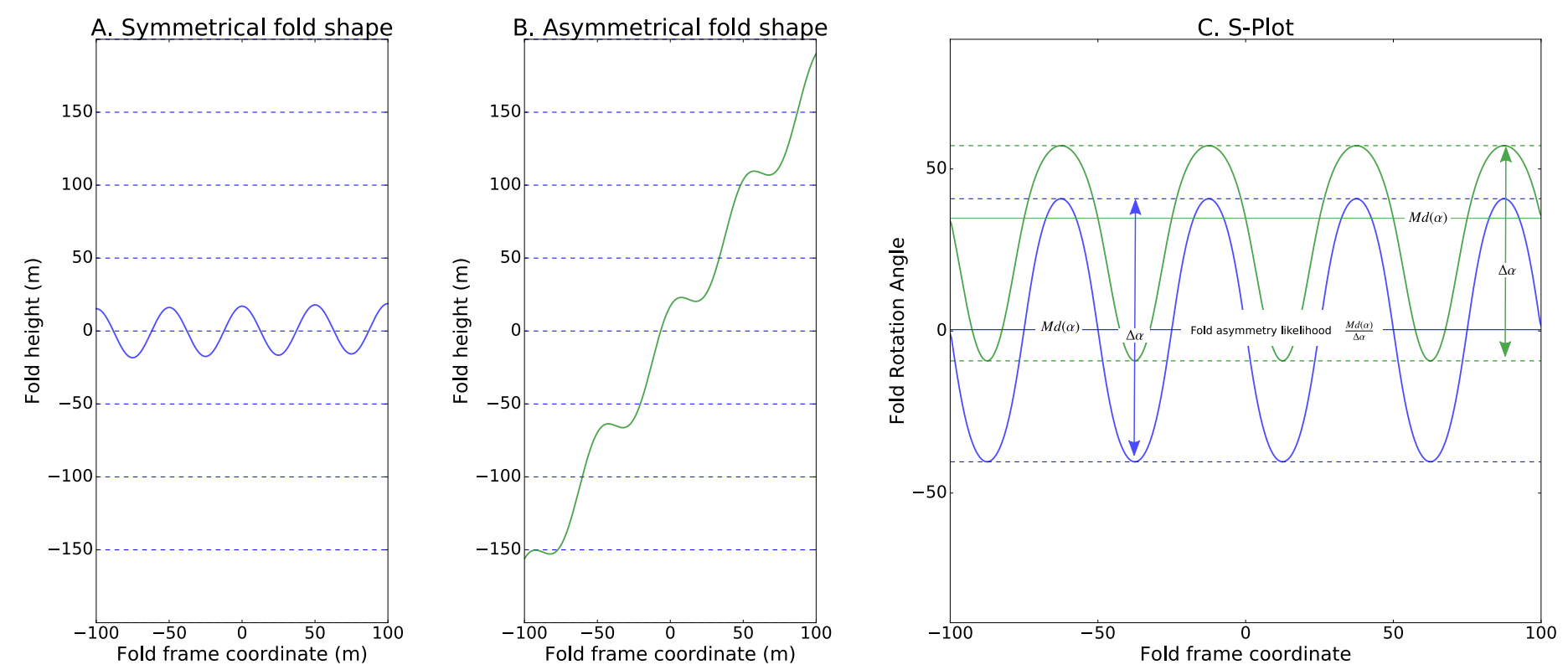

Figure 3 Fold asymmetry likelihood. A: Symmetrical fold shape B: Asymmetrical fold shape C: S-Plot showing fold rotation angle for fold in (A) and (B). $\Delta \alpha$ and $M d(\alpha)$ is shown for both fold rotation angle curves.

The fold rotation angles $(\hat{\alpha})$ can be corrected using a factor $j_{i}$ that follows a discrete uniform distribution with possible values of $[-1,1]$ :

$$
\hat{\alpha}^{*}=\hat{\alpha} \cdot j_{i}
$$

This approach allows for data to be corrected using an objective function integrated into the geological inversion, reducing the potential for uncertainty and bias to be introduced into the modeling during data correction and outlier identification.

\section{Results}

\subsection{Synthetic proof of concept examples}

In Fig. 4, the reference fold is a parasitic fold train that is only sampled in a single limb of the main fold. In this example, only a quarter wavelength of the main fold is captured in the data and the main fold wavelength cannot be identified using the S-Variogram (Fig. 4C). The geological inversion captures the main high frequency features in the S-Plot associated with the parasitic folds, but does not capture the main fold wavelength (Fig. 4E). The interpolated fold geometry (Fig. 4D) using the fold constraints with only a single wavelength prior (Fig. 4F) is unsatisfactory and only captures the smaller parasitic folds. While, the resulting 3D model may fit the structural observations, it would not fit the geologist's interpretation, which may be based on geological knowledge. Additional prior knowledge of the main fold wavelength can be incorporated using an informed prior distribution. For example, in Figs. 4G,H geological knowledge is incorporated using a prior distribution for an additional wavelength with a mean of $180 \mathrm{~m}$ (an overestimation of the true fold wavelength) and standard deviation of $60 \mathrm{~m}$. The posterior distribution for the main fold wavelength, $\lambda_{2}$ in Fig. $4 \mathrm{I}$, is slightly over estimated and the variability increases away from the structural observations. This effect could be reduced by using a more informative (smaller standard deviation) prior distribution. The inversion results also show an asymmetry in the main fold that is not seen in the reference model. The asymmetry of the large fold could be corrected using a fold symmetry likelihood function if geological knowledge suggests that the folding is symmetrical.

Fig. 5 contains examples using the different geological likelihood functions. The reference fold is a sinusoidal curve with a wavelength of $150 \mathrm{~m}$ and two data points are used. In all examples, the S-Plot curve for the reference fold is shown by the solid blue line in the plots on the left, with the data points (black circles) and the geological knowledge likelihood functions. The fold wavelength is constrained by an informed prior distribution with a mean of $150 \mathrm{~m}$ and standard deviation of $50 \mathrm{~m}$. In the first example (Fig. 5A1), geological knowledge is used to constrain the location of the fold hinges. The axial trace locations (red dots) have been intentionally offset from the true fold hinge location to simulate possible uncertainties. Fig. 5A2 shows the resulting fold rotation angle curves when only knowledge about the axial trace location and the fold symmetry are included in the inversion. A large range exists in the sampled fold geometries with significant variability in the tightness of the folds, seen in the range of the fold rotation angle for the inversion. The high variability can be addressed by including additional knowledge about the fold tightness in the inversion and results in a more concentrated posterior distribution (Fig. 5A3). In both of these examples, enough information in the two orientation observations exists to constrain the type of observed fold hinge (i.e. the slope of the S-Plot curve determines if the fold hinge is synformal or antiformal). However, if these points were closer together, the folding less tight or if no observations are available, the interpolated geometry should have an equal probability for synformal or antiformal hinges. In most practical cases, axial trace data usually contains some information about whether the fold hinge is synformal or antiformal, which could be included using vergence constraints.

In Fig. 5B1, structural vergence is known in five locations within the model area, shown by the arrows indicating the sign of the fold rotation angle. The inversion in Fig. 5B2 only uses structural vergence and fold symmetry knowledge. The resulting fold shapes have a similar wavelength to the reference model with some variability in the hinge locations particularly away from the data locations (e.g. $z>200)$. There is a wide range in fold tightness with folds ranging from close to isoclinal. When additional knowledge is used to constrain the fold tightness, the variability in the hinge locations is reduced (Fig. 5B3). The inversion results show a wavelength that is underestimated in comparison to the reference model, however the inversion results are consistent with the geological knowledge. Additional knowledge constrain- 
A. Fold profile

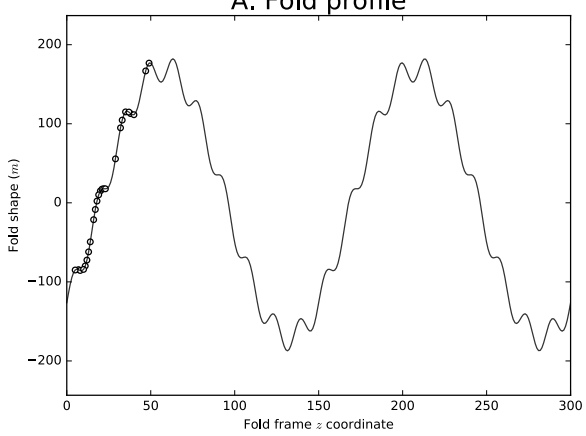

D. Inversion: fold shape

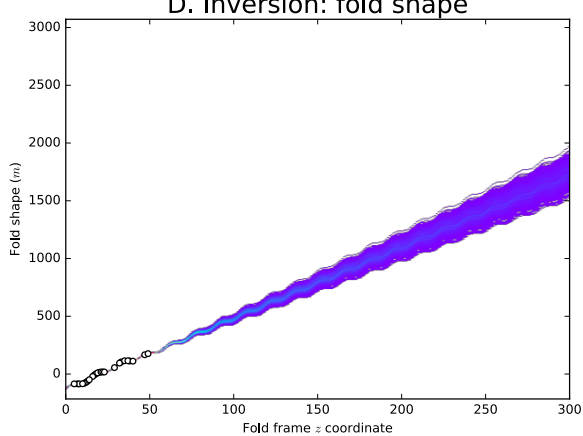

G. Inversion: fold shape

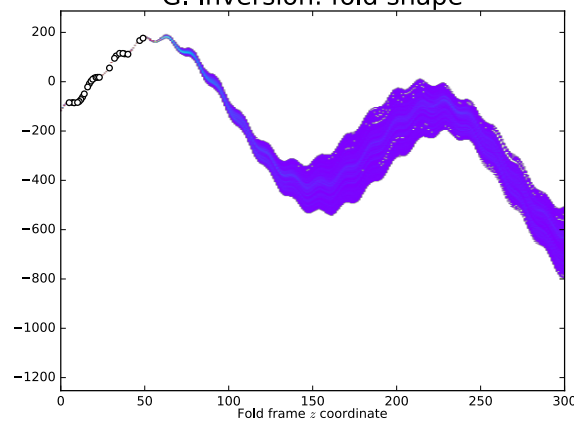

B. S-Plot

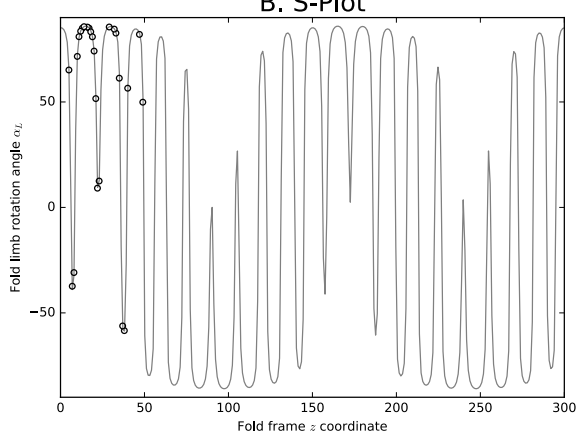

E. Inversion: fold rotation angle

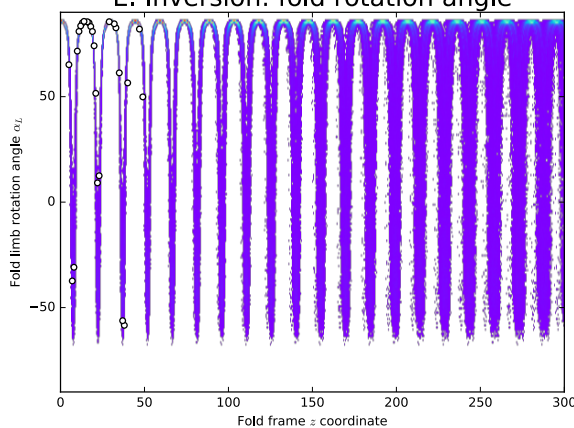

H. Inversion: fold rotation angle

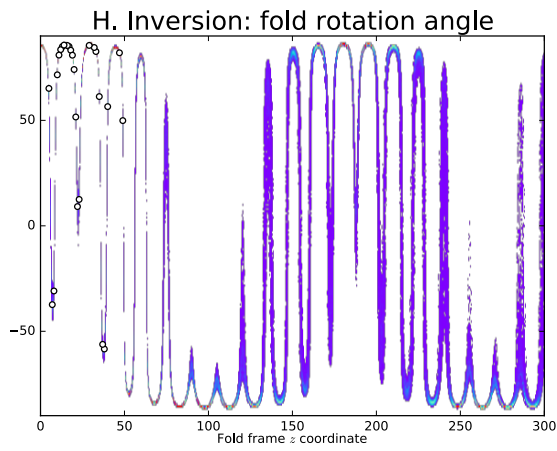

C. S-Variogram

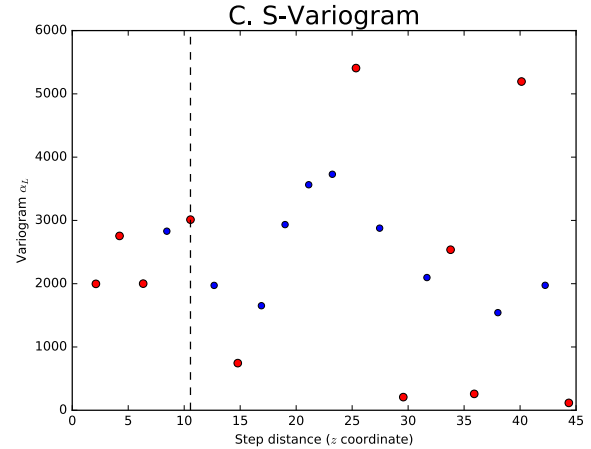

F. PDF for wavelength(s)

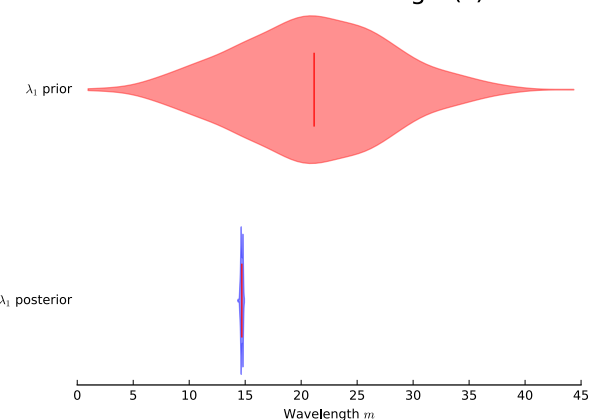

I. PDF for wavelength(s)
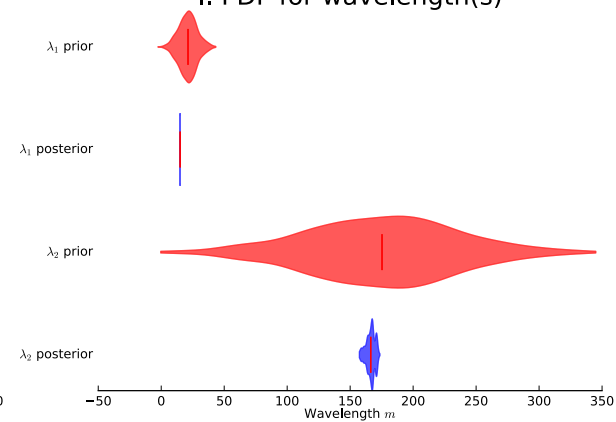

Figure 4 Parasitic fold shape with observations from a single fold limb: A: Reference parasitic fold shape sampled from only one fold limb. B: S-Plot showing reference fold rotation angle and sample locations. C: S-Variogram where only one fold wavelength is identified. D: Interpolated fold shape using only the single identified wavelength. E: Interpolated fold rotation angle. F: Prior and posterior distributions for wavelength parameter (D) and (E). G: Interpolated fold shape using prior knowledge about larger wavelength folding. H: Interpolated fold rotation angle using prior knowledge about larger wavelength folding. I: The prior and posterior distributions for the two fold wavelengths. Prior distribution for $\lambda_{2}$ represents additional geological knowledge.

ing the wavelength of the folds or the location of fold hinges could be included to reduce this variability.

In Fig. 5C1, two vergence observations are near the data points and an axial trace observation near the fold hinge where $z>250 \mathrm{~m}$. There are three interpolated fold hinges that are not captured by the geological knowledge or observations. Fig. 5C2 shows the resulting inversion where no knowledge about fold tightness is included. The inversion results show that the fold geometry is not well constrained using only this geological knowledge. The fold tightness contributes significantly to the variability with fold geometries ranging from open to close. In Fig. 5C3, the additional knowledge of the fold tightness significantly reduces the variability in the fold geometries. The fold tightness constraint not only reduces the range in the interpolated fold tightness but also makes the resulting fold wavelength more consistent to the reference model. This outcome indicates that knowledge related to the fold tightness is very important in constraining the resulting geometries.

In all previous examples, the polarity of the orientation data has been consistent, whereas in Fig. 6 the polarity of $35 \%$ of the data has been reversed. This difference is indicated by the direction of the arrows in Fig. 6A. The observations with reversed polarity do not fall on the reference curve for the fold rotation angle (Fig. 6B). The wavelength of the fold is usually estimated by finding the local maximum of the S-Variogram [Grose et al., 2017, 2018]. In this example, the $S$-Variogram has a large nugget effect (y intercept of semi-variogram), which suggests weak correlation between close data points Fig. 6C). This behaviour is because the sign of the calculated fold rotation angle changes with the polarity meaning that the correlation exists between two data points with inconsistent polarity would be small. In this case, the wavelength was able to be estimated to be $\sim 160 \mathrm{~m}$. In some cases, for example, where too many data points have inconsistent polarity, it may not be possible to use the S-Variogram to estimate the wavelength. In these cases, the wavelength could either be defined using geological knowledge using an informative prior, or the S-Variogram could be calculated using the absolute value of the fold rotation angle. When the absolute value of the fold rotation angle is used, the local maximum would correlate with the quarter wavelength of the fold. Fig. 6D and E show the interpolated fold shape and fold rotation angles where the polarity is assumed to be correct. The posterior distribution for the wavelength is consistent with 

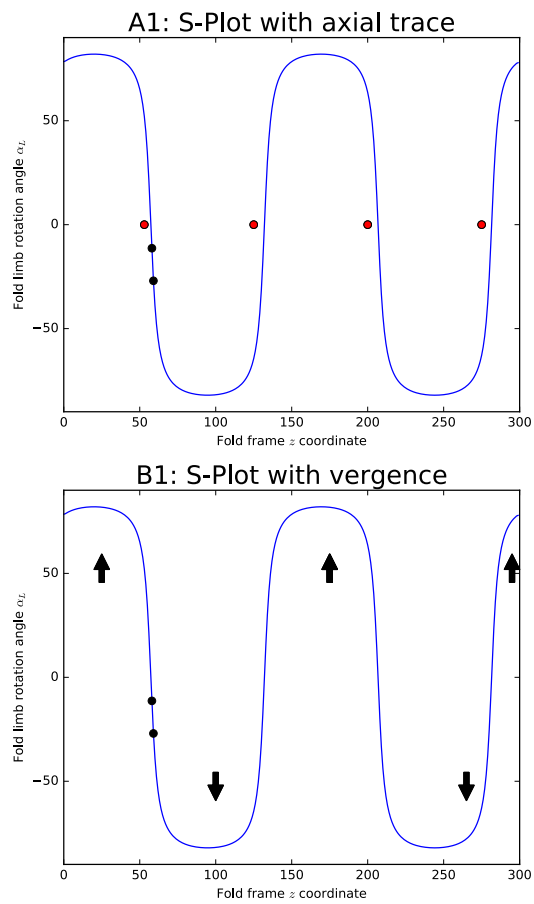

C1: S-Plot with vergence and axial trace

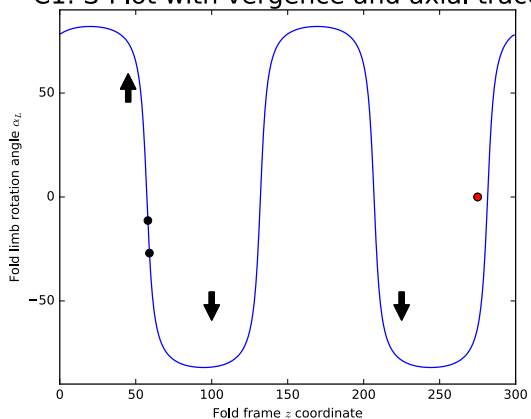

A2: S-Plot fold rotation without fold tightness

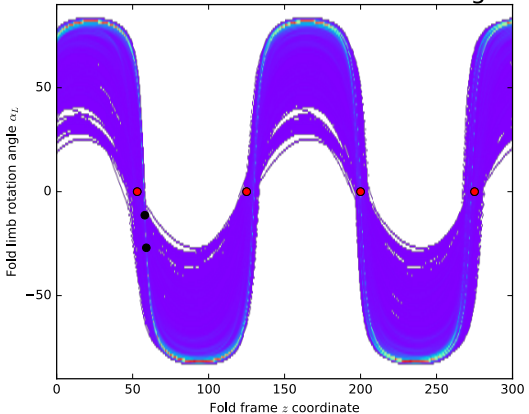

B2: S-Plot fold rotation without fold tightness

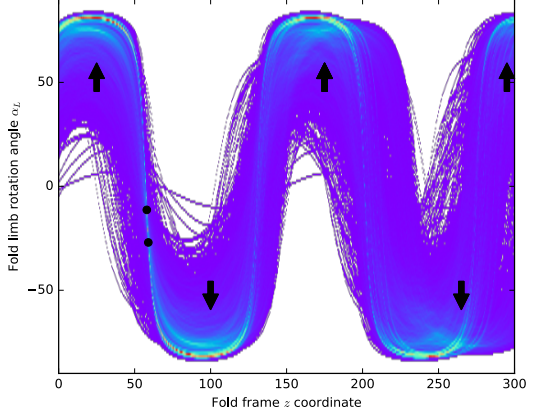

C2: S-Plot fold rotation without fold tightness

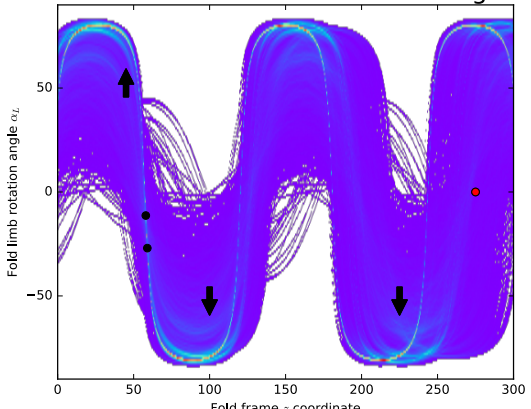

A3: S-Plot fold rotation with fold tightness

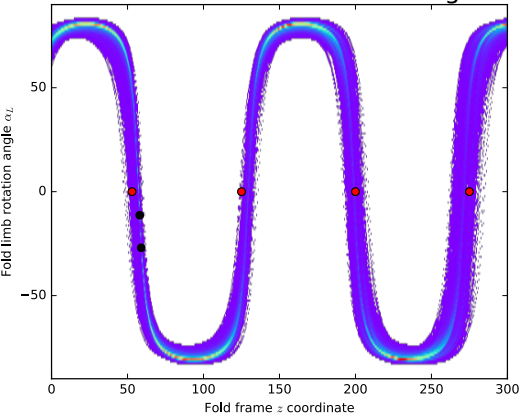

B3: S-Plot fold rotation with fold tightness

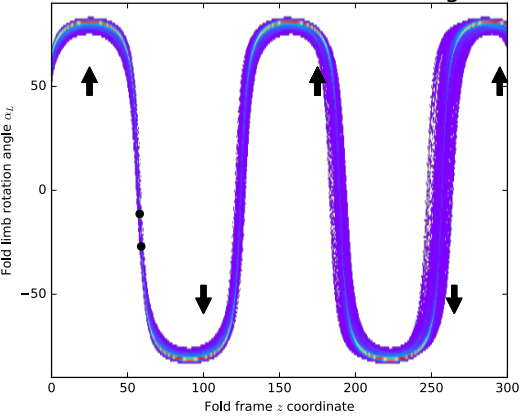

C3: S-Plot fold rotation with fold tightness

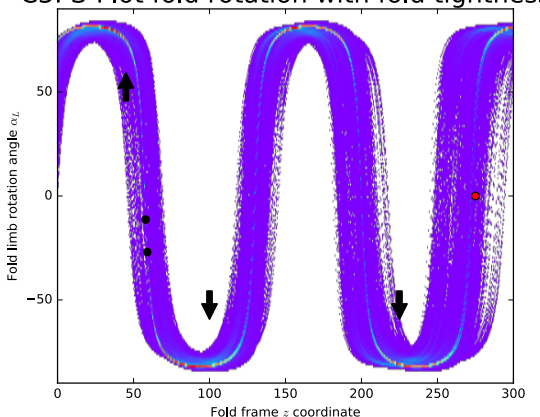

Figure 5 Synthetic examples demonstrating different geological knowledge likelihood functions. A1: Reference S-Plot showing axial trace locations (red dots) and two surface orientation constraints (black dots). A2: Simulated fold rotation angles using data, axial trace and asymmetry likelihoods. A3: Using the same constraints as (A2) and interlimb angle likelihood. B1: Reference S-Plot showing vergence observation location (black arrows) and two surface orientation constraints (black dots). B2: Simulated fold rotation angles using data, axial trace and asymmetry likelihoods. B3: Using the same constraints as (A2) and interlimb angle likelihood. C1: Reference S-Plot showing axial trace location (red dots), vergence constraints black arrows and two surface orientation constraints (black dots). C2: Simulated fold rotation angles using data, axial trace, vergence and asymmetry likelihoods. A3: Using the same constraints as (C2) and interlimb angle likelihood.

the reference geometry $(150 m)$ Fig. $6 \mathrm{~F}$. However, there is significant variability associated with the fold geometry. When the polarity is incorporated into the inversion using Eq. (3), all of the observations with incorrect polarity are identified and the interpolated fold shape and fold profile (Fig. 6G,H) match the reference model. The addition of Eq. (3) results in the posterior distribution of the wavelength (Fig. 6I) having a reduced standard deviation, meaning that accounting for the incorrect polarity improves the fit of the models to the data.

\subsection{Case study: Davenport Province}

In the final example, we demonstrate an inversion of geological observations and knowledge using a case study from the Davenport Province, a poly-deformed fold belt in the Northern Territory, Australia. It is a well exposed Proterozoic terrane where mainly sedimentary packages have been folded to form a Type 1 interference pattern during the Paleoproterozoic Barramundi Orogeny [Blake and Page, 1988]. Fig. 7A shows the location of the Davenport Province, in Northern Australia and a simplified geological map shows the main fold axial traces and stratigraphic units.
The model area (Fig. 7B) contains three major northwestsoutheast trending, doubly plunging folds: the Devils Marbles anticline (north), Curtis syncline and the Ridgewall anticline (south). The structural observations have been digitized from the publicly available Bonney Well map sheet. The folds have a half wavelength of approximately $7 \mathrm{~km}$ and can be clearly seen in aerial imagery (Fig. 7B). Only the orientation of bedding has been recorded and no direct observations were made of the fold axis or axial foliations. The associated cross section [Stewart et al., 1986] suggests that the folding is upright, and we use this interpretation to constrain the geometry of the axial foliation with the interpreted axial trace locations.

The orientation of the axial foliation has not been recorded, meaning that an appropriate assumption is used to describe the observed fold geometry as a Type 1 interference pattern as suggested by Blake and Page [1988]. Type 1 fold interference patterns can be represented with a single fold frame where the $z$ coordinate is aligned at best with the axial traces of the northwestsoutheast folds and the $y$ coordinate is interpolated to align with the axial trace of the northeast-southwest folds. If two fold frames were to be used, the $z$ and $y$ coordinates for the two folding events 

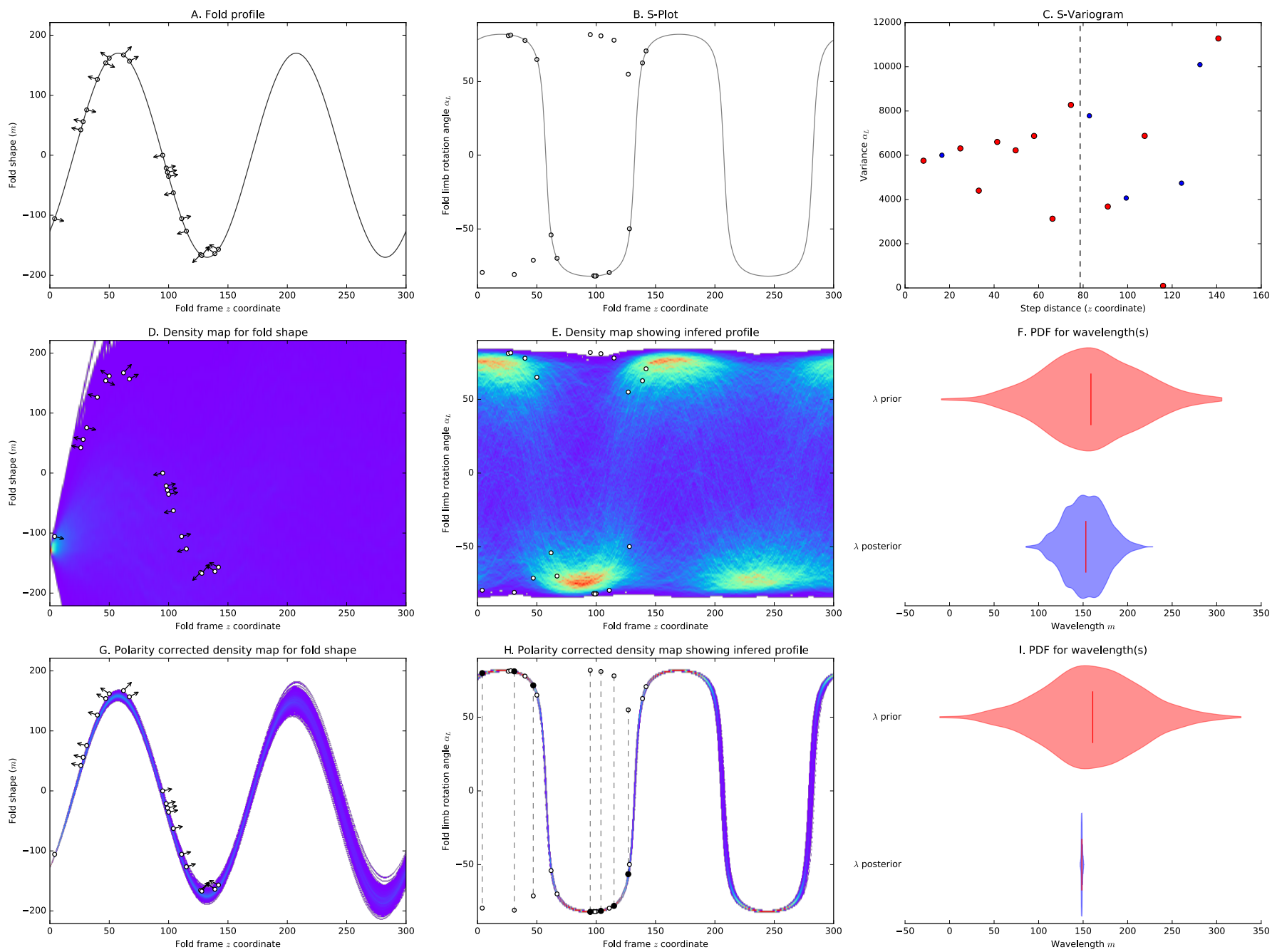

Figure 6 A: Reference fold shape of a sinusoidal fold with inconsistent polarity shown by the direction of the arrows located at the observations. B: Fold rotation angle reference curve and the calculated rotation angle showing the effect of polarity on the sign of the calculated rotation angle. C: S-Variogram showing a high nugget effect due to the incorrect polarity for 7 observations. Dashed line indicates the estimated fold wavelength. D: Interpolated fold shape without polarity correction. E: Interpolated fold rotation curve without polarity correction. F: Prior and posterior distributions for the wavelength parameter for (D) and (E). G: Interpolated fold shape showing corrected polarity using Eq. (3), observation polarity has been corrected. H: Interpolated fold rotation curve using Eq. (3), dashed lines show the data points that have been corrected and the black dots indicate the corrected fold rotation values. I: Prior and posterior distributions for the wavelength parameter for $(\mathrm{G})$ and $(\mathrm{H})$.

would be close to parallel. This approach does make the assumption that the axial surface of the older fold is not folded by the younger folding event. The interpolated scalar fields for the fold frame $y$ and $z$ coordinates are shown in Fig. 8. We use the assumption that the folding is similar meaning that the $x$ coordinate does not need to be interpolated. To constrain the orientation of the fold axis, Grose et al. [2017] use the intersection of the $z$ coordinate isosurfaces and orientation of the folded foliation. However, because the fold frame has not been constrained with field observations, this technique results in very inconsistent calculated fold rotation angles (Fig. 9A). For example, the calculated fold axis rotation angle for $y=-30,000$ is between $-40^{\circ}$ and $10^{\circ}$.

Using the aerial imagery and the interpolated fold frame it is possible to infer the fold hinge line vergence and use this to constrain the fold axis rotation angle. The orientation of bedding in the fold hinge can be used to determine the geometry of the fold axis. For example, the Devils Marbles antiform plunges shallowly east and $e_{y}$ is oriented to the east suggesting the fold axis rotation angle should be negative in this area. Most bedding observations in the fold hinge suggest a shallowly plunging fold where the dip of bedding is about $30^{\circ}$. The dip seems to be consistent on each fold hinge, which suggests that the fold axis is symmetrically folded and would have an equivalent fold axis rotation angle range to a gentle fold shape (Table 1). These observations can be included in the fold geometry inversion using fold symmetry and fold hinge angle likelihood function. The fold limb rotation angle is well constrained by the observations of bedding. This is incorporated into the inversion using the geological knowledge likelihood functions to constrain the fold axis geometry to be symmetrical with a range in the fold axis rotation angle of $60^{\circ}$ and three hinge-line vergence constraints inferred from the analysis of the aerial photography and structural observations. The half wavelength of the fold axis is constrained by measuring the average distance between plunging fold hinges, of approximately $50 \mathrm{~km}$. The joint posterior distribution for the fold axis rotation angle and fold limb rotation angle is shown in Fig. 9E and F. The variability between the profiles increases away from the data for the fold limb rotation angle, suggesting high uncertainty, where the $z$ coordinate is greater than $5,000 \mathrm{~m}$.

Fig. 10A shows the geometrical variability in the inversion results with the highest variability being associated with the northwest- southeast folding. There is also variability associated 

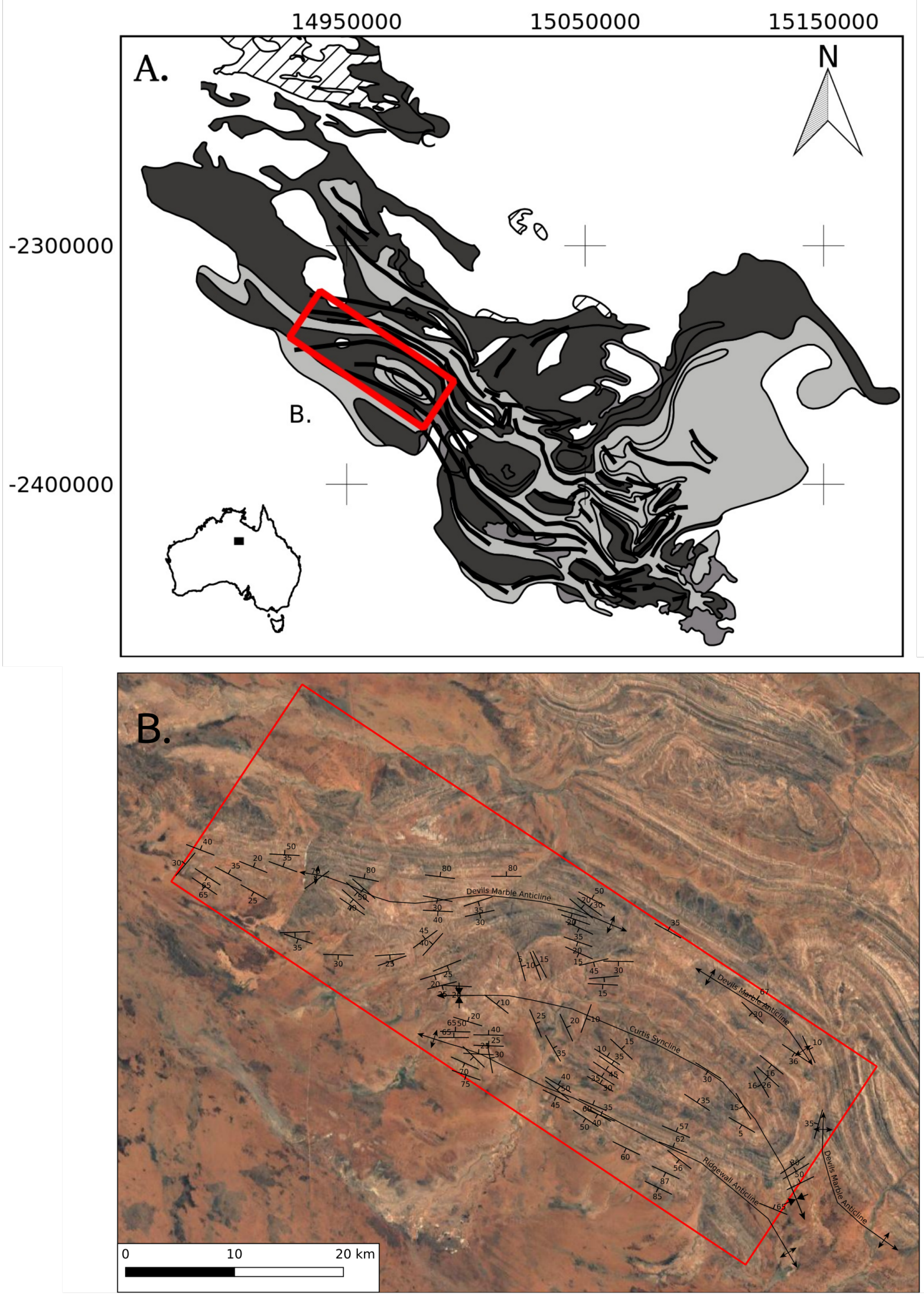

Fold axial trace

Arumbera Sandstone

Lower Hatches Creek Group and Flynn Subgroup Upper Hatches Creek Group

Warramunga Formation $+\quad$ Orientation of bedding

$\uparrow \uparrow$ Antiform axial trace

Synform axial trace Model area

Figure 7 A. Simplified geological map showing the Proterozoic rocks from the Davenport Province, adapted from Stewart et al. [1986] projected using GDA94 Zone 54. B. Structural map for study area from Stewart et al. [1986] 


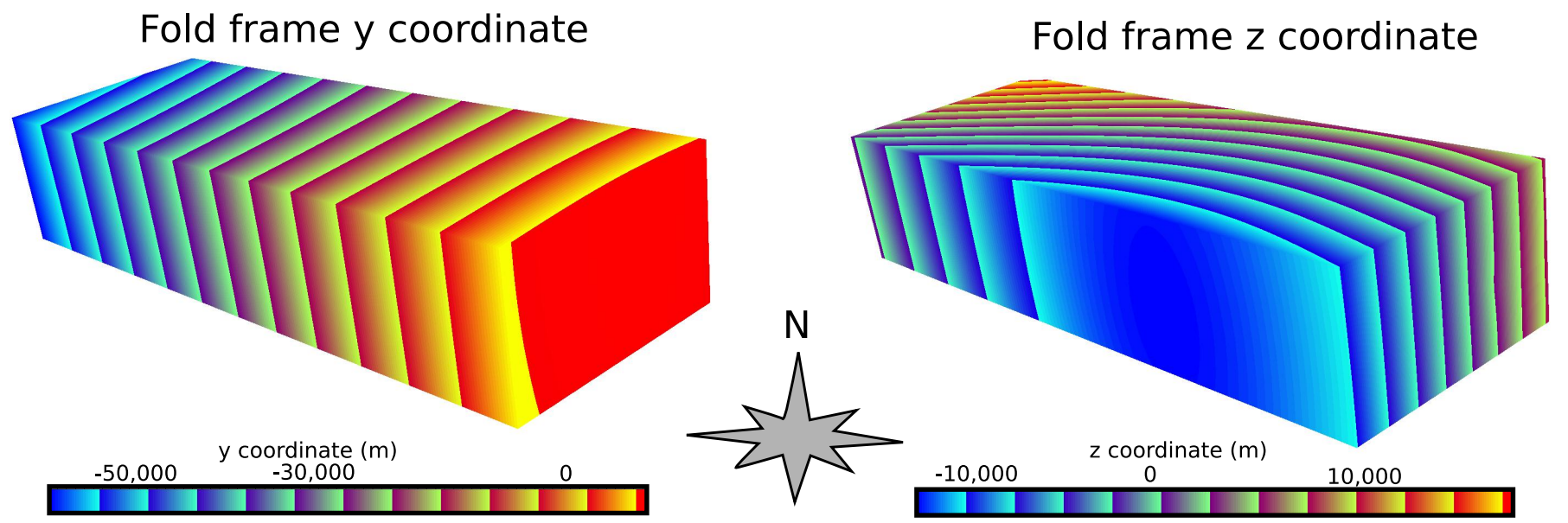

Figure 8 Interpolated volumes showing the $y$ and $z$ fold frame coordinate scalar fields. The $y$ coordinate represents the distance from a reference fold apex. The $z$ coordinate measures the distance from a reference axial surface.
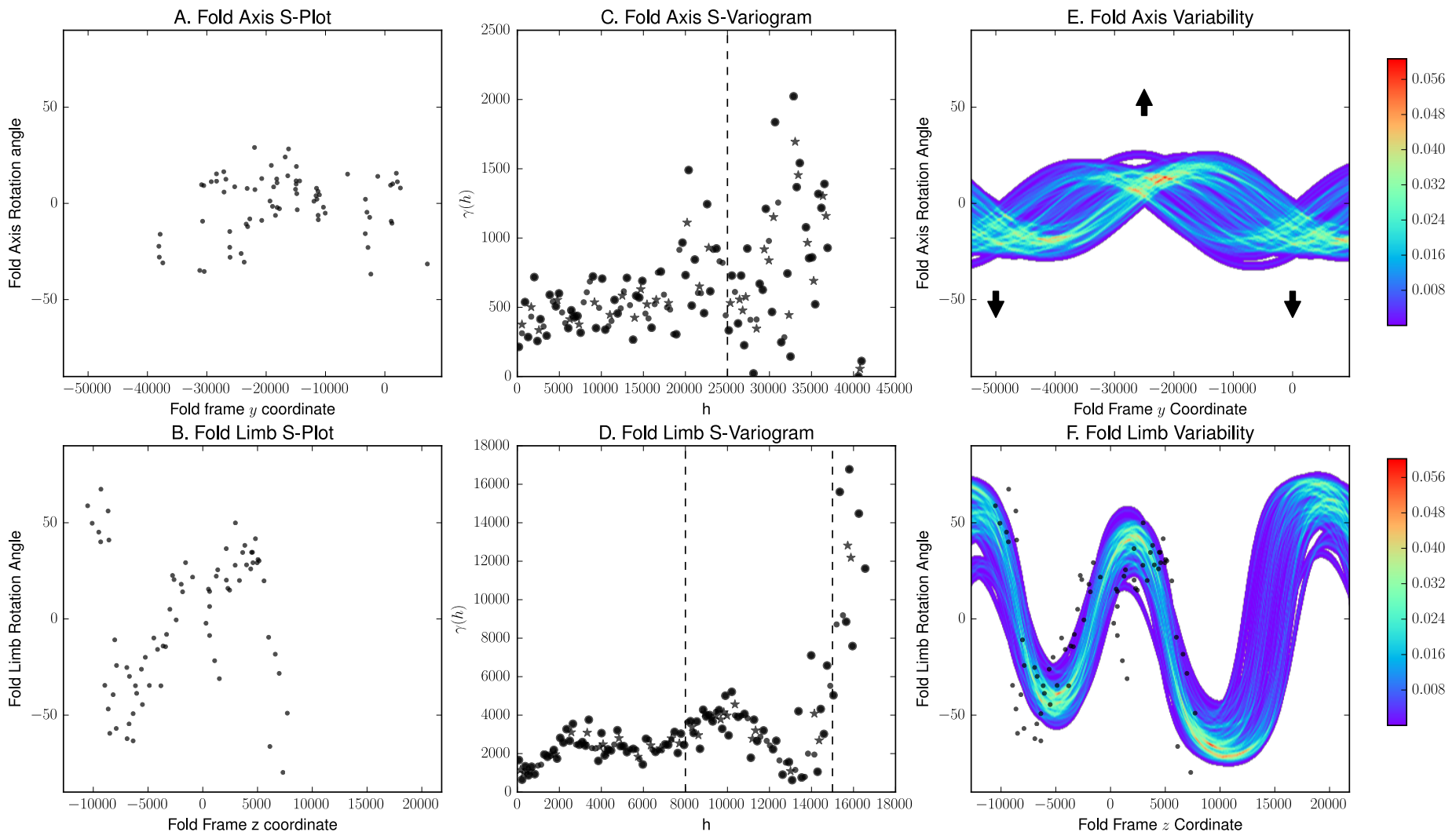

Figure 9 A. S-Plot of fold axis rotation angle. B. Fold limb rotation angle S-plot. C. Fold axis S-Variogram. D. Fold limb rotation angle S-Variogram. E. Interpolated fold axis rotation angle. F. Interpolated fold limb rotation angle.

with the interpolated fold axis that can be seen by the change in angle variability along the interpolated fold hinge locations (Fig. 10A). The interpolated surfaces all capture the main geometries of the observed map pattern. The location of largest variability is associated with the fold north of the Devils Marble anticline. The interpolated surfaces are all very steeply dipping approaching vertical. This is in agreement with the recorded orientation of bedding which is consistently dipping $80^{\circ}$. The geological interpretation in the cross section suggests a more open fold geometry with less steeply dipping limbs.

In Fig. 11B the frequency of form lines corresponding to a single isosurface for all 200 inversion realisations are shown by a scaled colour map. The areas with higher frequency correspond to the locations where the geometry is more consistent between inversion realisations. The axial traces of the major folds high- lights that the main structural features observed in the aerial photography are captured by the geological inversion (Fig. 11A). For example, the basin associated with the Curtis syncline is highlighted by the absence of any form lines. Areas of large variability between the interpolated form lines, such as the location of the syncline to the north of the Devils Marble anticline, present targets for additional data collection.

\section{Discussion}

3D geological models are constructed using available geological observations that directly constrain the surfaces being modeled. Geological knowledge has usually been incorporated into the modeling process by the geologist first interpreting the resulting geometry and adding in interpretive constraints [Jessell et al., 2010a, 2014; Maxelon et al., 2009]. In this contribution, 


\section{A. Angle variability model volume}

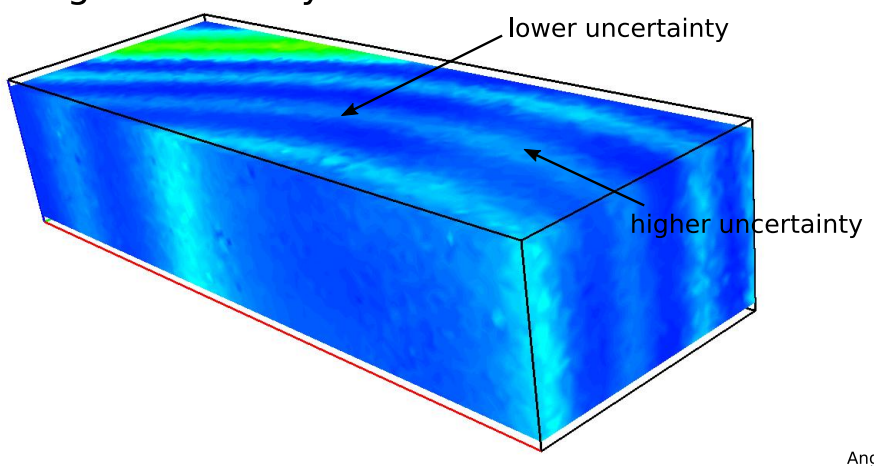

\section{B. Angle variability model slices}

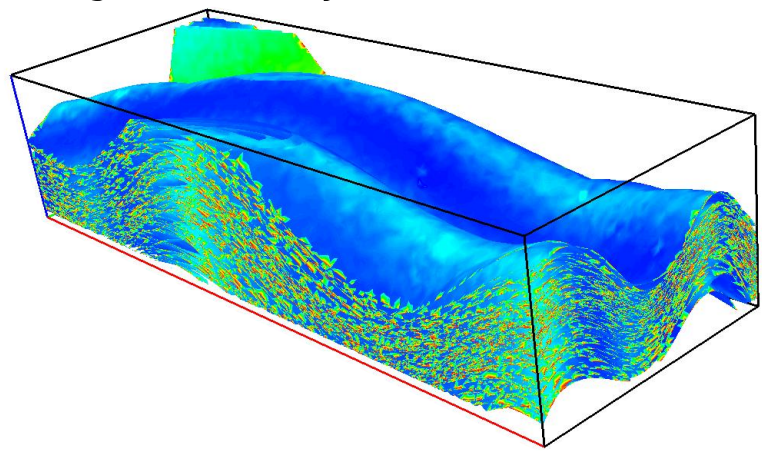

60

80

Figure 10 A. Geometrical variability between 100 interpolated models highlighting lower and higher areas of uncertainty along fold hinge. B. Surface from 100 models painted with angle variability indicating the consistency of the modeling to the observed structural features. Maps are projected using GDA94 Zone 54

A. Davenport Province: Aerial imagery and main folds

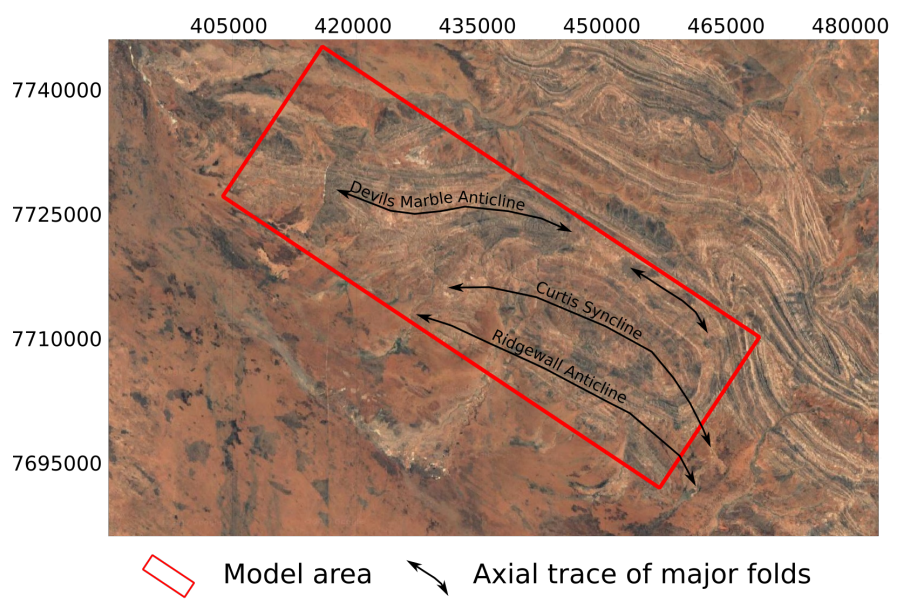

B. Davenport Province: Model suite form line frequency

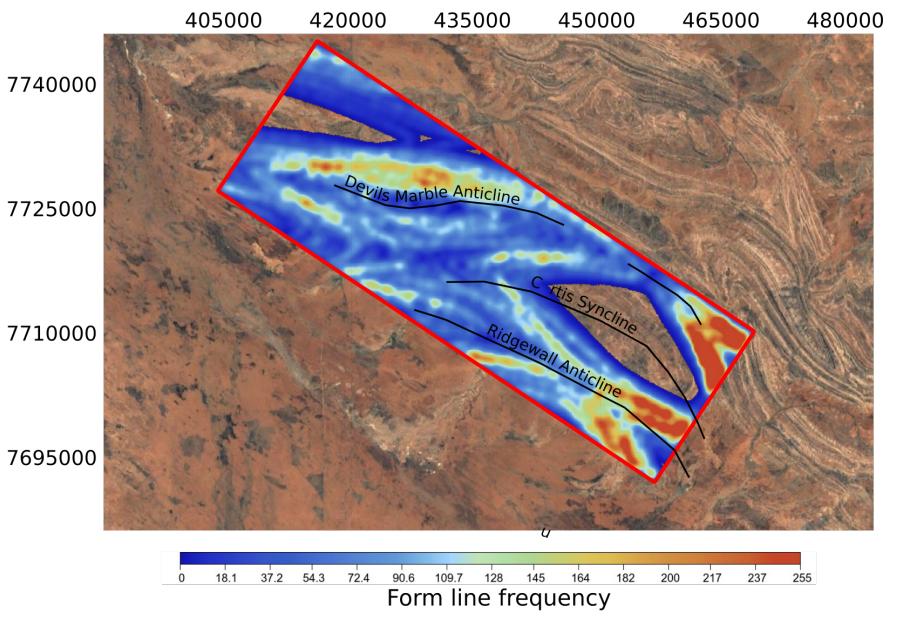

Figure 11 Resulting geological uncertainty of a single form surface intersecting topography for all inversion results overlain on aerial imagery.

we have used the flexibility of Bayesian inference to combine both geological data and knowledge into a geological inversion scheme [Grose et al., 2018]. The addition of these constraints can significantly reduce the range of possible fold geometries specifically where geological data is sparse or ambiguous (e.g. Fig. 5). In all examples, the fold tightness constraint significantly reduces the variability between the inversion realisations. This outcome is an expected result as the majority of the observed variability between fold geometries was in the inferred tightness. This constraint could be applied by upscaling tightness observed at an outcrop scale to the geometry of the folds being modeled.

The fold axis geometry is an important part of the fold modeling workflow and often only limited observations are recorded on geological maps. It is important that the fold axis is consistent with the structural observations and the geologists knowledge because the fold limb rotation angle is calculated in the plane normal to the fold axis [Grose et al., 2017, 2018]. Where the geometry becomes more complicated and more uncertainty exists in structural observations, calculating the intersection between the interpolated $z$ coordinate and folded foliation does not provide a good constraint for the geometry of the fold axis (e.g. Fig. 9A). This failure will result in fold geometries that are much more extreme than the observed folding. In Fig. 9E and F, the joint posterior distribution was sampled using only the geological knowledge likelihood functions for the fold axis and the data points for the fold limb rotation angle. It is possible that the best fitting model for both observations and knowledge would not be produced without directly using geological knowledge within the inversion scheme. This issue becomes even more important if form lines are used to calculate the fold limb rotation angle because there is no 3D information in the form line, the best solution for the fold axis minimises the range in fold limb rotation angle.

A number of studies have inverstigated uncertainties in geological interpretations [e.g. Bond et al., 2007a, 2011; Torvela and Bond, 2011; Bond et al., 2015]. These studies have primarily focused on the interpretation of seismic datasets and have provided interesting insight into the role of experience and expertise in geological interpretation. In their study, Bond et al. [2007a] used a cohort of geologists with skill levels ranging from experienced geologists to students. All of the cohort were shown to exhibit availability bias where they were more likely to interpret the tectonic setting they had the most experience with. This observation is consistent with Frodeman [1995]'s interpretation of geology as a historical science, where analogies are an important part of geological reasoning. For seismic interpretation, the geologist may use the structural style they are familiar with as an analogy for the interpretation area. Anchoring bias also affected the interpretations across the cohort where the interpreters expected to see a particular structure for a given setting. Similarly, the interpreters were seeking confirmation for their interpretations by asking the 
geographical location, to infer the broad tectonic setting of the study area. These observations by Bond et al. [2007a] suggest that the interpretive aspect of geology plays a significant role throughout the interpretation of geological datasets. In a structural mapping context, these results suggest that while mapping, the geologists current interpretation plays a significant role for guiding both outcrop interpretation and often in identifying the next location to map. In a study following the path taken by undergraduates during field mapping, Riggs et al. [2009] find that more advanced students systematically test multiple interpretations resulting in better geological maps.

Jones et al. [2004] argue that advances in digital field mapping could allow for the separation of interpretation from raw field data. They propose interpretation tools that could use geological uncertainties associated with individual data and/or interpretations as the input to produce an overall estimate of the uncertainty associated with a given model. This approach would allow for alternative interpretations to be modeled simultaneously, during mapping and ultimately would guide the geologist in data collection. Fig. 11B shows how the inversion framework presented in this paper could be used for real time geological mapping. This type of output could be incorporated as a dynamic layer in a digital mapping program allowing the geologist to interact with multiple possible interpretations. In Fig. 11B, a single contact has been interpolated and the outcrop pattern used as a proxy for model variability. Areas of high variability are associated with the fold geometries and can be used to help target additional data for reducing the geological variability. Additionally, producing a 3D realisation of geological structures during field mapping would allow for more targeted data collection in areas with higher variability or structures conflicting with the geologists hypothesis For example, in the Davenport Province model, more uncertainty is associated with the fold hinges in the north-western area of the model. This result suggested that more data could be collected to either better constrain the orientation of the folded surface or to better constrain the orientation of the axial foliation. Building 3D models while collecting data would be advantageous because the geologists knowledge would be used to falsify possible models, effectively as an additional likelihood function for the model. This approach means that the geologists expertise can be applied to assessing how well the interpretation fits the observations rather than producing a single best-fit model [Wijns et al., 2003; Jessell et al., 2010a]. While it will never be possible to completely remove the subjectivity from geological studies, moving towards a quantitative interpretation approach should reduce the impact of bias on geological reasoning as multiple possible interpretations are presented to the geologist rather than the geologist generally trying to falsify a single interpretation. The application to the Davenport Province has demonstrated that the method can be successfully applied to a poly-deformed structure. In this case study, there was insufficient data constraining the geometry of the axial foliation. Additional observations would allow for multiple fold events to be inverted and would result in a much better representation of the geological structures. Applying our inversion framework during geological mapping would allow geologists to test how different interpretations fit the observations rather than trying to identify the best interpretation.

A common approach for trying to reduce geological ambiguity/uncertainty is the use of geophysical inversions to help understand the geometry and distribution of subsurface geology [e.g. Fullagar et al., 2004; Guillen et al., 2008; Blaikie et al., 2014; Armit et al., 2014; McLean et al., 2008]. Prior geological knowledge (e.g. an existing 3D model) can be used to perform a con- strained inversion. The geometry, density and/or magnetic susceptibility of the rock units are then stochastically varied to reduce the misfit between the inversion and observed geophysics. However, these inversion approaches typically do not maintain any geological meaning when producing the inversion [Jessell et al., 2010a]. When performing a geometrical inversion, the model geometries are perturbed by locally varying the stratigraphic unit without consideration for the type of geological structure or the topological relationship between geological units. This simplication can result in model geometries that fit the geophysics but are geological implausible. One approach [Lindsay et al., 2013a,b] to maintaining the geological meaning in the models is to use the results from geological uncertainty simulations as prior geological models for the inversion. This approach considers the geologically possible models prior to using the geophysical observations. However, this technique does not allow for the geophysical inversion to inform the geological model. A true joint geological and geophysical inversion would combine the sampling of the posterior distribution to sample using both geological likelihood functions and geophysical likelihood functions [Jessell et al., 2010a]. It would be expected that the posterior distribution of possible models considering geophysical and geological observations will be different to the posterior distribution of either property independently. In much the same way as adding in additional knowledge reduces the variability in the interpolated fold shapes, adding geophysical data provides a means of falsifying models that cannot fit the geophysical observations. This approach has not been previously feasible because 3D modeling schemes have been unable to predict the full range of geological observations. However, using the recent developments in fold modeling [Laurent et al., 2016; Grose et al., 2017, 2018] and this paper, as well as methods for simulating fault networks [Cherpeau et al., 2012; Cherpeau and Caumon, 2015] and incorporate knowledge related to fault geometries [de la Varga and Wellmann, 2016; Laurent et al., 2013], a joint geological and geophysical inversion becomes more feasible.

\section{Conclusion}

New geological likelihood functions are proposed for integrating additional geological data and knowledge into an inversion scheme for fold geometries. Geological knowledge is incorporated directly into the interpolation scheme using Bayesian inference. This allows for poorly constrained features such as the fold axes to be modeled with minimal hard data and still produce results consistent with the geological interpretation. The incorporation of geological knowledge directly into the interpolation scheme could form the basis of a real-time geological inversion that could be used to help to address the ambiguity in geological interpretations. This approach would allow for information about geological uncertainties to propagate while mapping and allow for different structural interpretations to be rapidly tested for targeted data collection.

Our geological inversion scheme is unique because it uses the geological observations to falsify possible structural models built from a parameterised description of the fold geometry using prior geological knowledge, instead of using observations to infer a single best model or a suite of models based on observation uncertainties. We believe that this approach is not only a more rigorous way of sampling the geologically possible models but also will allow for a true joint geological and geophysical inversion. 


\section{Acknowledgements}

This research was partially funded by Australian Research Council Linkage grant LP140100267, and partly supported by the "Investissements d'avenir" Labex RESSOURCES21 (ANR10-LABX-21-01). The authors are grateful to the industrial and academic sponsors of the Gocad Research Consortium managed by ASGA (Association Scientifique pour la Géologie et ses Applications, http://ring.georessources.univ-lorraine.fr/) for their support. We thank Paradigm for providing the GOCADSKUA software and API. The final case study in this publication was generated with the StructuralFactory plugin for Gocad, based on RING's StructuralLab plugin. Jupyter notebooks for the synthetic examples can be obtained from www.github.com/lachlangrose/inverting_knowledge_JSG. 3D examples and software can be obtained by contacting the corresponding author. The authors would like to thank Dr. Rick Allmendinger and an anonymous reviewer for constructive comments that have greatly improved the quality of the manuscript. We also thank Bill Dunne for the efficient editorial process.

\section{References}

P. Calcagno, J.P. Chilès, G. Courrioux, and A. Guillen. Geological modelling from field data and geological knowledge. Physics of the Earth and Planetary Interiors, 171(1-4):147-157, 2008. ISSN 00319201. doi: 10.1016/j.pepi. 2008.06.013. (Cited page 1)

Cecile Massiot and Guillaume Caumon. Accounting for axial directions, cleavages and folding style during 3D structural modeling. In 30th Gocad Meeting Proceedings, 2010. (Cited page 1)

Guillaume Caumon, Gary Gray, Christophe Antoine, and Marc-Olivier Titeux. Three-Dimensional Implicit Stratigraphic Model Building From Remote Sensing Data on Tetrahedral Meshes: Theory and Application to a Regional Model of La Popa Basin, NE Mexico. IEEE Transactions on Geoscience and Remote Sensing, 51(3):1613-1621, 2013. ISSN 0196-2892. doi: 10.1109/TGRS.2012.2207727. (Cited page 1)

Michael Hillier, Eric de Kemp, and Ernst Schetselaar. 3D form line construction by structural field interpolation (SFI) of geologic strike and dip observations. Journal of Structural Geology, 51:167-179, 2013. ISSN 01918141. doi: 10.1016/j.jsg.2013.01.012. (Cited page 1)

Michael J. Hillier, Ernst M. Schetselaar, Eric A. de Kemp, and Gervais Perron. Three-Dimensional Modelling of Geological Surfaces Using Generalized Interpolation with Radial Basis Functions. Mathematical Geosciences, 46 (8):931-953, 2014. ISSN 1874-8961. doi: 10.1007/s11004-014-9540-3. (Cited page 1)

Gautier Laurent, Laurent Ailleres, Lachlan Grose, Guillaume Caumon, Mark Jessell, and Robin Armit. Implicit modeling of folds and overprinting deformation. Earth and Planetary Science Letters, 456:26-38, 2016. ISSN 0012821X. doi: 10.1016/j.eps1.2016.09.040. (Cited pages 1, 2, 4, and 13)

Lachlan Grose, Gautier Laurent, Laurent Aillères, Robin Armit, Mark Jessell, and Guillaume Caumon. Structural data constraints for implicit modeling of folds. Journal of Structural Geology, 104:80-92, 2017. ISSN 01918141. doi: 10.1016/j.jsg.2017.09.013. (Cited pages 1, 2, 3, 4, 5, 7, 9, 12, and 13)

L. Grose, G. Laurent, L. Aillères, R. Armit, M. Jessell, and T. Cousin-Dechenaud Inversion of structural geology data for fold geometry. Journal of Geophysical Research: Solid Earth, 123(8):6318-6333, 2018. ISSN 21699313. doi: 10.1029/2017JB015177. (Cited pages 1, 2, 3, 4, 5, 7, 12, and 13)

Ej Cowan, Rk Beatson, Hj Ross, Wr Fright, Tj McLennan, Tr Evans, Jc Carr, Rg Lane, Dv Bright, Aj Gillman, Pa Oshust, and M Titley. Practical implicit geological modelling. 5th International Mining Geology Conference, (8): 89-99, 2003. ISSN 01489062. (Cited page 1)

Mark W. Jessell, Laurent Ailleres, and Eric A. de Kemp. Towards an integrated inversion of geoscientific data: What price of geology? Tectonophysics, 490 (3-4):294-306, 2010a. ISSN 00401951. doi: 10.1016/j.tecto.2010.05.020. (Cited pages 1, 11, and 13)

Mark Jessell, Laurent Aillères, Eric De Kemp, Mark Lindsay, Florian Wellmann, Michael Hillier, Gautier Laurent, Thomas Carmichael, and Roland Martin. Next generation 3D geological modelling and inversion. In Society of Economic Geologists Special Publication 18, chapter 13, pages 261-272. 2014 (Cited pages 1 and 11)

Richard R. Jones, Kenneth J. W. McCaffrey, Robert W. Wilson, and Robert E. Holdsworth. Digital field data acquisition: towards increased quantification of uncertainty during geological mapping. Geological Society, London, Special
Publications, 239(1):43-56, 2004. ISSN 0305-8719. doi: 10.1144/GSL.SP. 2004.239.01.04. (Cited pages 1, 2, and 13)

Alberto Malinverno and Robert L. Parker. Two ways to quantify uncertainty in geophysical inverse problems. Geophysics, 71(3):W15-W27, 2006. ISSN 0016-8033. doi: 10.1190/1.2194516. (Cited pages 1 and 4)

Rachel Wood and Andrew Curtis. Geological prior information and its applications to geoscientific problems. Geological Society, London, Special Publications, 239(1):1-14, 2004. ISSN 0305-8719. doi: 10.1144/GSL.SP.2004.239. 01.01. (Cited page 1)

J Florian Wellmann, Miguel D E L A Varga, Ruth E Murdie, Klaus Gessner, Mark Jessell, Miguel de la Varga, Ruth E Murdie, Klaus Gessner, and Mark Jessell. Uncertainty estimation for a geological model of the Sandstone greenstone belt, Western Australia $\{\backslash$ textendash $\}$ insights from integrated geological and geophysical inversion in a Bayesian inference framework. Geological Society, London, Special Publications, 453, 2017. ISSN 0305-8719. doi: 10.1144/ SP453.12. (Cited pages 2 and 4)

Miguel de la Varga and J. Florian Wellmann. Structural geologic modeling as an inference problem: A Bayesian perspective. Interpretation, 4(3):1-16, 2016. ISSN 2324-8858. doi: 10.1190/INT-2015-0188.1. (Cited pages 2, 4, and 13)

Martin J S Rudwick. The Emergence of a Visual Language for Geological Science 1760-1840. History of Science, 14(3):149-195, 1976. doi: 10.1177/ 007327537601400301. (Cited page 2)

Robert Frodeman. Geological reasoning: Geology as an interpretive and historical science. Geological Society of America Bulletin, 107(8):9600968, 1995. ISSN 00167606. doi: 10.1130/0016-7606(1995)107<0960: GRGAAI $>2.3 . \mathrm{CO} ; 2$. (Cited pages 2 and 12)

Clare E. Bond, A. D. Gibbs, Z. K. Shipton, and S. Jones. What do you think this is? "Conceptual uncertainty" In geoscience interpretation. GSA Today, 17(11):4-10, 2007a. ISSN 10525173. doi: 10.1130/GSAT01711A.1. (Cited pages 2, 12, and 13)

Eric M. Riggs, Christopher C. Lieder, and Russell Balliet. Geologic Problem Solving in the Field: Analysis of Field Navigation and Mapping by Advanced Undergraduates. Journal of Geoscience Education, 57(1):48-63, 2009. ISSN 1089-9995. doi: 10.5408/1.3559525. (Cited pages 2 and 13)

Mark W. Jessell, Laurent Ailleres, and Eric A. de Kemp. Towards an integrated inversion of geoscientific data: What price of geology? Tectonophysics, 490 (3-4):294-306, 2010b. ISSN 00401951. doi: 10.1016/j.tecto.2010.05.020. (Cited page 2)

Chris Wijns, Fabio Boschetti, and Louis Moresi. Inverse modelling in geology by interactive evolutionary computation. Journal of Structural Geology, 25(10): 1615-1621, 2003. ISSN 0191-8141. doi: 10.1016/S0191-8141(03)00010-5. (Cited pages 2 and 13)

K.J.W. McCaffrey, R.R. Jones, R.E. Holdsworth, R.W. Wilson, P. Clegg, J. Imber, N. Holliman, and I. Trinks. Unlocking the spatial dimension: digital technologies and the future of geoscience fieldwork. Journal of the Geological Society, 162(6):927-938, 2005. ISSN 0016-7649. doi: 10.1144/0016-764905-017. (Cited page 2)

C.E. Bond, Z.K. Shipton, R.R. Jones, R.W.H. Butler, and A.D. Gibbs. Knowledge transfer in a digital world: Field data acquisition, uncertainty, visualization, and data management. Geosphere, 3(6):568, 2007b. ISSN 1553-040X. doi: 10.1130/GES00094.1. (Cited page 2)

Albert Tarantola. Popper, Bayes and the inverse problem. Nature Physics, 2(8): 492-494, 2006. ISSN 1745-2473. doi: 10.1038/nphys375. (Cited page 3)

Anand Patil, David Huard, and Christopher J Fonnesbeck. PyMC: Bayesian Stochastic Modelling in Python. Journal of statistical software, 35(4):1-81, 2010. ISSN 1548-7660. doi: 10.18637/jss.v035.i04. (Cited page 3)

D S Sivia. Data analysis : a Bayesian tutorial. Oxford : Clarendon Press, Oxford : New York, 1996. ISBN 0198518897. (Cited page 3)

M.J. Fleuty. The description of folds. Proceedings of the Geologists' Association, 75(4):461-492, 1964. ISSN 00167878. doi: 10.1016/S0016-7878(64) 80023-7. (Cited page 4)

G. D. Williams and T. J. Chapman. The geometrical classification of noncylindrical folds. Journal of Structural Geology, 1(3):181-185, 1979. ISSN 01918141. doi: 10.1016/0191-8141(79)90038-5. (Cited page 4)

Fernando Bastida, Jesús Aller, Nilo C. Bobillo-Ares, and Noel C. Toimil. Fold geometry: A basis for their kinematical analysis. Earth-Science Reviews, 70:129-164, 2005. ISSN 00128252. doi: 10.1016/j.earscirev.2004.11.006. (Cited page 4)

A.M. Bell. Vergence: an evaluation. Journal of Structural Geology, 3(3): 197-202, 1981. ISSN 01918141. doi: 10.1016/0191-8141(81)90015-8. (Cited page 4)

G. I. Alsop and R. E. Holdsworth. Vergence and facing patterns in large-scale sheath folds. Journal of Structural Geology, 21(10):1335-1349, 1999. ISSN 01918141. doi: 10.1016/S0191-8141(99)00099-1. (Cited page 4) 
P.J. Hudleston. Fold morphology and some geometrical implications of theories of fold development. Tectonophysics, 16(1-2):1-46, 1973. ISSN 00401951. doi: 10.1016/0040-1951(73)90129-7. (Cited page 5)

D Blake and R Page. The Proterozoic Davenport province, central Australia: regional geology and geochronology. Precambrian Research, 40-41:329-340, 1988. ISSN 03019268. doi: 10.1016/0301-9268(88)90074-5. (Cited page 8)

A. J. Stewart, D. H. Blake, and S. Wyche. Booney Well Sheet SF53-2 Second Edition. Australia 1:250 000 Geological Series, 1986. (Cited pages 8 and 10)

Michael Maxelon, Philippe Renard, Gabriel Courrioux, Martin Braendli, Neil S Mancktelow, Martin Brändli, Neil S Mancktelow, Martin Braendli, and Neil S Mancktelow. A workflow to facilitate three-dimensional geometrical modelling of complex poly-deformed geological units. Computers $\mathcal{E}$ Geosciences, 35(3):644-658, 2009. ISSN 0098-3004. doi: 10.1016/j.cageo.2008.06.005. (Cited page 11)

Clare Elizabeth Bond, Chris Philo, and Zoe Kai Shipton. When there isn't a right answer: Interpretation and reasoning, key skills for twenty-first century geoscience. International Journal of Science Education, 33(5):629-652, 2011 ISSN 09500693. doi: 10.1080/09500691003660364. (Cited page 12)

Taija Torvela and Clare E Bond. Do experts use idealised structural models? Insights from a deepwater fold-thrust belt. Journal of Structural Geology, 33(1):51-58, 2011. ISSN 0191-8141. doi: 10.1016/j.jsg.2010.10.002. (Cited page 12)

C. E. Bond, G. Johnson, and J. F. Ellis. Structural model creation: the impact of data type and creative space on geological reasoning and interpretation. Geological Society, London, Special Publications, 421(1):83-97, 2015. ISSN 0305-8719. doi: 10.1144/SP421.4. (Cited page 12)

P.K. Fullagar, Glenn Pears, David Hutton, and Andrew Thompson. 3D gravity and aeromagnetic inversion for MVT lead-zinc exploration at Pillara, Western Australia. Exploration Geophysics, 35(2):142, 2004. ISSN 0812-3985. doi: 10.1071/EG04142. (Cited page 13)

A. Guillen, Ph Calcagno, G. Courrioux, A. Joly, and P. Ledru. Geological modelling from field data and geological knowledge. Physics of the Earth and Planetary Interiors, 171(1-4):158-169, 2008. ISSN 00319201. doi: 10.1016/j.pepi.2008.06.014. (Cited page 13)

T.N. Blaikie, L. Ailleres, P. G. Betts, and R. A.F. Cas. Interpreting subsurface volcanic structures using geologically constrained 3-D gravity inversions: Examples of maar-diatremes, Newer Volcanics Province, southeastern Australia Journal of Geophysical Research: Solid Earth, 119(4):3857-3878, 2014. doi: 10.1002/2013JB010751. (Cited page 13)

R. J. Armit, L. Ailleres, P. G. Betts, B. F. Schaefer, and T. N. Blaikie. Highheat geodynamic setting during the Palaeozoic evolution of the Mount Painter Province, SA, Australia: Evidence from combined field structural geology and potential-field inversions. Geophysical Journal International, 199(1) 253-275, 2014. ISSN 1365246X. doi: 10.1093/gji/ggu263. (Cited page 13)

Mark A. McLean, Timothy J. Rawling, Peter G. Betts, Glen Phillips, and Chris J.L. Wilson. Three-dimensional inversion modelling of a Neoproterozoic basin in the southern Prince Charles Mountains, East Antarctica. Tectonophysics, 456(3-4):180-193, 2008. ISSN 00401951. doi: 10.1016/j.tecto.2008.04.023. (Cited page 13)

M.D. Lindsay, M.W. Jessell, L. Ailleres, S. Perrouty, E. de Kemp, and P.G. Betts Geodiversity: Exploration of 3D geological model space. Tectonophysics, 594:27-37, 2013a. ISSN 00401951. doi: 10.1016/j.tecto.2013.03.013 (Cited page 13)

M. D. Lindsay, S. Perrouty, M. W. Jessell, and L. Ailleres. Making the link between geological and geophysical uncertainty: geodiversity in the Ashanti Greenstone Belt. Geophysical Journal International, 195(2):903-922, 2013b. ISSN 0956-540X. doi: 10.1093/gji/ggt311. (Cited page 13)

Nicolas Cherpeau, Guillaume Caumon, Jef Caers, and Bruno Lévy. Method for Stochastic Inverse Modeling of Fault Geometry and Connectivity Using Flow Data. Mathematical Geosciences, 44(2):147-168, 2012. ISSN 1874-8961. doi: 10.1007/s11004-012-9389-2. (Cited page 13)

Nicolas Cherpeau and Guillaume Caumon. Stochastic structural modelling in sparse data situations. Petroleum Geoscience, 21(4):233-247, 2015. ISSN 1354-0793. doi: 10.1144/petgeo2013-030. (Cited page 13)

Gautier Laurent, Guillaume Caumon, Antoine Bouziat, and Mark Jessell. A parametric method to model 3D displacements around faults with volumetric vector fields. Tectonophysics, 590:83-93, 2013. ISSN 00401951. doi 10.1016/j.tecto.2013.01.015. (Cited page 13) 